\title{
Population Pharmacokinetic Analysis of Tiropramide in Healthy Korean Subjects
}

\author{
Seung-Hyun Jeong ${ }^{1,+}$, Ji-Hun Jang ${ }^{1,+}$, Hea-Young Cho ${ }^{2} \mathbb{C}$ and Yong-Bok Lee ${ }^{1, *} \mathbb{C}$ \\ 1 College of Pharmacy, Chonnam National University, 77 Yongbong-ro, Buk-Gu, Gwangju 61186, Korea; \\ rhdqn95@naver.com (S.-H.J.); jangi10121@naver.com (J.-H.J.) \\ 2 College of Pharmacy, CHA University, 335 Pangyo-ro, Bundang-gu, Seongnam-si, \\ Gyeonggi-Do 13488, Korea; hycho@cha.ac.kr \\ * Correspondence: leeyb@chonnam.ac.kr; Tel.: +82-62-530-2931; Fax: +82-62-530-0106 \\ + Both authors contributed equally to this work.
}

Received: 9 March 2020; Accepted: 17 April 2020; Published: 18 April 2020

check for

\begin{abstract}
The purpose of this study was to perform population pharmacokinetic (PPK) analysis of tiropramide in healthy Korean subjects, as well as to investigate the possible effects of various covariates on pharmacokinetic (PK) parameters of tiropramide. Although tiropramide is commonly used in digestive system-related diseases as an antispasmodic, PPK reporting and factors affecting PKs are not clearly reported. Thus, this study for healthy subjects is very significant because it could find new covariates in patients that had not been reported before or predict PPK for patients in the clinic by establishing PPK in healthy adults. By using Phoenix NLME, PK, demographic, and genetic data (collected to explain PK diversity of tiropramide in population) analyses were performed. As a basic model, a one-compartment with first-order absorption and lag-time was established and extended to include covariates that influenced the inter-subject variability. The total protein significantly influenced the distribution volume and systemic clearance of tiropramide, but genetic factors such as $A B C B 1(1236 \mathrm{C}>\mathrm{T}, 2677 \mathrm{G}>\mathrm{T} / \mathrm{A}$, and $3435 \mathrm{C}>\mathrm{T}), \mathrm{CYP} 2 \mathrm{D} 6\left({ }^{*} 1\right.$ and $\left.{ }^{*} 10\right)$, OCT2 $(808 \mathrm{G}>\mathrm{T})$, and PEPT1 $(1287 \mathrm{G}>\mathrm{C})$ genes did not show any significant association with PK parameters of tiropramide. The final PPK model of tiropramide was validated, and suggested that some of the PK diversity in the population could be explained. Herein, we first describe the establishment of the PPK model of tiropramide for healthy Korean subjects, which may be useful as a dosing algorithm for the diseased population.
\end{abstract}

Keywords: tiropramide; healthy Korean subjects; modeling; population pharmacokinetic

\section{Introduction}

Tiropramide is a drug that has been used from the past to the present for symptom relief and treatment of diseases of the digestive system such as acute spastic abdominal pain and irritable bowel syndrome. Tiropramide is a structurally equivalent tyrosine derivative and contains amide functional groups in the structure together with tertiary amines. It has been reported that tiropramide is widely metabolized into various metabolites (hydroxytiropramide, $N$-despropyltiropramide, $\mathrm{N}$-desethyltiropramide, and $\mathrm{N}$-desethyl- $\mathrm{N}$-despropyltiropramide) after oral administration to rats and humans [1-3]. The mechanism of action of tiropramide has been reported to directly affect the smooth muscle cells. That is, tiropramide activates intracellular cyclic adenosine monophosphate (cAMP) synthase (adenylcyclase) to increase the amount of cAMP to regulate calcium ions necessary for muscle contraction, thereby controlling the relaxation and contraction of intestinal smooth muscle cells. This mechanism of action is very important for clinical use. Other antispasmodics include anticholinergics or antimuscarinics that relieve abdominal pain by acting on the intestinal nervous 
system. However, the mechanism of action on the nervous system may cause systemic side effects such as dry mouth, dry eyes, and drowsiness, which may lower the patients' compliance with medication. As a result, tiropramide has been widely used in the clinic for the treatment of diseases related to the digestive system with the reduction of the systemic side effects.

However, reporting of pharmacokinetic (PK) information of tiropramide for humans is still very limited. Above all, tiropramide's population pharmacokinetics (PPK) have not been reported thus far. Tiropramide has been reported to have hypotension and peripheral vasodilation (as side effects) like other anticholinergic or antimuscarinic drugs only when a high dose is administered. Overall, incidences of tiropramide side effects are very low and a very safe profile in humans has been reported [4]. Although the incidence of adverse effects of tiropramide is reported to be low in humans, optimal dosing algorithm may maximize the therapeutic effect of the drug and reduce its adverse effects by using a PPK model. PPK modeling can enable effective dose setting and individualized pharmacotherapy by quantifying the diversity of the drug concentrations among individuals (in the population) with a variety of related physicochemical factors. In addition, identifying the physicochemical factors affecting PKs of tiropramide will be a significant scientific basis for the clinical application (such as usage and dose settings) and formulation of tiropramide in the future.

Tiropramide is usually administered orally to adults at $100 \mathrm{mg}$ ( 1 tablet) $2-3$ times a day in the clinic. In exceptional cases, it is reported that tiropramide may be additionally administered in cases of less symptomatic relief. However, it is difficult to judge whether these levels of capacity and usage are precise when considering the differences among individuals in the population. More scientific evidence and data on the dose setting and safety of tiropramide are needed. Therefore, we thought that a study of the PPK model of tiropramide was necessary. In addition, it begs the question on how the various physicochemical or genetic factors among individuals in the population affect the PKs of tiropramide. Moreover, even if individual physicochemical or genetic factors affect tiropramide's PKs, it is very doubtful as to how large the effect would be. Finding significant covariates of tiropramide is very difficult due to the lack of detailed PK information on the precise metabolic mechanisms, absorption, distribution, and excretion of tiropramide (especially in humans), and no PPK studies have been reported in the past. Therefore, in this study, we set up a variety of candidate covariates early in the study to establish factors that significantly influence the PK of tiropramide. The process was based on the physicochemical or physiological properties of tiropramide that have been reported to date.

Tiropramide has amine groups in its structure and will be basic at $\mathrm{pH}$ (about 7.4) in vivo on the basis of its pKa value (of 3.1) [4]. Therefore, the covariate effect was confirmed by genotyping the OCT gene, which is known to be related to the absorption, distribution, and excretion of various organic cations [5]. Tiropramide is a substance derived from the amino acid tyrosine [6]. Therefore, the genotyping of the PEPT gene, which is known to be involved in the absorption and distribution of the peptide drugs such as peptides and $\beta$-lactam antibiotics, was performed to confirm the covariate effect [7]. P-glycoprotein (P-gp) is a transporter with a broad range of substrate specificities of about $170 \mathrm{kDa}$ and is known to be mainly involved in the efflux of neutral or cationic substances. In addition, $A B C B 1$ has been reported as a gene that encodes the P-gp. In this study, the covariate effect was confirmed by genotyping $A B C B 1$ [8]. In the past, the metabolism of tiropramide in the liver was examined [1], and the covariate effect was confirmed by genotyping metabolism-related CYP2D6. In particular, we focused on single nucleotide polymorphism (SNP) of the CYP2D6 gene related to phase I metabolism (oxidation, reduction, hydrolysis, etc.) in the liver, and tried to confirm the correlation with PKs [9]. In addition, we collected information on various physicochemical factors (including general functional indicators of the kidney and liver) and sought to find the major covariates affecting PKs.

We report on PPK modeling of tiropramide in this study, together with factors affecting PK diversity in the population, which have not been reported yet. In the tiropramide final PPK model (of this study), we quantitatively reflected on the total protein, physicochemical, or genetic factors with differences between individuals, suggesting that scientific dose setting can be possible. In these 
aspects, for clinical applications, the tiropramide's PPK model would be a great advantage. As a result, development of a tiropramide's PPK model for use in healthy Korean subjects was the purpose of this study. The developed tiropramide's PPK model is expected to be useful for determining a valuable dosing algorithm for tiropramide in healthy Korean subjects. In addition, the identification of factors affecting PK of tiropramide is expected to be of great help in related future studies.

\section{Methods}

\subsection{Study Design}

Samples obtained from a bioequivalence study of tiropramide in 24 healthy Korean males were included in this analysis. The age of these subjects ranged from 19 to 29 years (mean \pm standard deviation (SD), $22.96 \pm 2.61$ years). Their body weights ranged from 55.2 to $82.8 \mathrm{~kg}$ (mean $\pm \mathrm{SD}$, $67.60 \pm 7.28 \mathrm{~kg}$ ). Their body surface area (BSA) ranged from 1.58 to $1.97 \mathrm{~m}^{2}$ (mean $\pm \mathrm{SD}, 1.80 \pm 0.11 \mathrm{~m}^{2}$ ), and their body mass index (BMI) ranged from 17.89 to $29.06 \mathrm{~kg} / \mathrm{m}^{2}$ (mean $\pm \mathrm{SD}, 22.74 \pm 2.72 \mathrm{~kg} / \mathrm{m}^{2}$ ). Each subject had no hypersensitivity to any drugs or previous history of illness and was physically normal. All subjects provided informed written consent to perform bioequivalence and PK studies. All subjects underwent physical examinations, clinical screening, complete blood count, urinalysis, and analysis of blood chemistry prior to the admission of this study to evaluate their physical health status. If subjects were taking any medications, other drugs, and/or alcohol for at least 1 week prior to this study, they were excluded from this study. The Institutional Review Board of the Institute of Bioequivalence and Bridging Study, Chonnam National University, Gwangju, Republic of Korea, reviewed and approved (Bioequivalence Test no. 875; 01.16.2003) this study protocol. Clinical studies were performed in accordance with rules of good clinical practice and the revised Declaration of Helsinki for biomedical research involving human subjects. Bioequivalence studies were performed as randomized, single-dose, open-label, crossover, and two-way studies. The data from reference formulation were only used for the current analysis. The subjects were hospitalized (Chonnam National University Hospital, Gwangju, Korea) at 7:30 p.m. 1 day before the study. The subjects had a heparin-locked catheter installed in the median cubital vein. A single dose (100 $\mathrm{mg})$ of tiropramide was given orally to all subjects (after an overnight fast) in each study group with $240 \mathrm{~mL}$ of water. Before administration $(0 \mathrm{~h})$ and at $0.33,0.67,1,1.5,2,2.5,3,4,6,8$, and $12 \mathrm{~h}$ after oral administration, blood samples $(8 \mathrm{~mL})$ were collected into Vacutainer tubes. At the time of blood sampling, about $2 \mathrm{~mL}$ of blood was drained each time to completely remove the heparinized saline solution remaining in the IV catheter, and about $8 \mathrm{~mL}$ of blood was collected. Following centrifugation (for $20 \mathrm{~min}$, at $5000 \times g$ ), plasma samples were obtained and transferred to polyethylene tubes. They were then stored at $-80^{\circ} \mathrm{C}$ until analysis. Another study was repeated in the same manner to complete the crossover design after a washout period of 7 days.

\subsection{Determination of Physicochemical Parameters}

Plasma samples were used in the determination of physicochemical parameters, including total proteins, aspartate transaminase (AST), albumin, alkaline phosphatase (ALP), alanine transaminase (ALT), and creatinine. The determination of main physicochemical parameters in this study, such as total proteins, albumin, AST, ALT, ALP, and creatinine, was performed in a dry automatic analyzer by microsides VITROS (Ortho Clinical Diagnostics, NJ, USA) operating by reflectance spectrophotometry.

\subsection{Determination of Genotypes}

The blood samples of $3 \mathrm{~mL}$, obtained from individuals participating in this study, were used for genotyping. The blood samples were centrifuged for $10 \mathrm{~min}$ at $1000 \times g$, and deoxyribonucleic acid (DNA) was extracted from the leukocyte layer using a Wizard Genomic DNA purification kit (Promega Co., Madison, WI, USA). The extracted DNA was dissolved in $100 \mu \mathrm{L}$ of DNA hydration solution and stored at $-70{ }^{\circ} \mathrm{C}$ until analysis. In order to amplify a portion of gene containing a SNP 
by polymerase chain reaction (PCR) from the extracted DNA, each primer was prepared according to the variation of allele. Moreover, the genotypes were determined using appropriate methods that have been reported in the past $[5,8,10,11]$. We conducted experiments three times to acquire exact genotype data.

\subsubsection{Identification of ABCB1 1236C > T (in Exon 12), 2677G $>\mathrm{T} / \mathrm{A}$ (in Exon 21), and 3435C > T (in Exon 26)}

Candidate SNPs $(1236 \mathrm{C}>\mathrm{T}, 2677 \mathrm{G}>\mathrm{T} / \mathrm{A}$, and 3435C $>\mathrm{T})$ in the $A B C B 1$ gene were genotyped by using polymerase chain reaction-restriction fragment length polymorphism (PCR-RFLP). Each primer was prepared according to the variation of allele. Forward primer of $5^{\prime}$-TATCCTGTGTCTGTGAATTGCC-3' and reverse primer of 5'-CCTGACTCACCACACACCAATG-3' were used for ABCB1 1236C>T

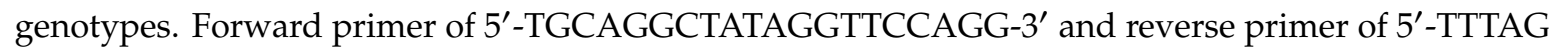
TTTGACTCACCT TCCCG-3' were used for determination of $A B C B 1$ 2677G>T/A genotypes. Forward primer of 5' $5^{\prime}$ TGTTTTCAGCTGCTTGATGG-3' and reverse primer of 5' -AAGGCATGTAT GTTGGCCTC-3' were used for $A B C B 13435 \mathrm{C}>\mathrm{T}$ genotypes. PCR was performed in $20 \mu \mathrm{L}$ reaction mixture including $1 \mu \mathrm{L}$ of 10 pmol each primer (forward and reverse), $1 \mu \mathrm{L}$ extracted DNA, and $17 \mu \mathrm{L}$ autoclaved distilled water. The PCR program was composed of an initial denaturation at $94{ }^{\circ} \mathrm{C}$ for 2 min followed by 35 cycles of denaturation at $94{ }^{\circ} \mathrm{C}$ for $30 \mathrm{~s}$, annealing at $59.8^{\circ} \mathrm{C}$ for $30 \mathrm{~s}$, and extension at $72{ }^{\circ} \mathrm{C}$ for $30 \mathrm{~s}$. The final extension step was performed at $72{ }^{\circ} \mathrm{C}$ for $5 \mathrm{~min}$. The DNA fragments amplified by PCR were reacted at $37^{\circ} \mathrm{C}$ for $16 \mathrm{~h}$ with restriction enzymes HaeIII (for $A B C B 1$ 1236C $>\mathrm{T}$ ), Sau3AI (for $A B C B 13435 \mathrm{C}>\mathrm{T}$ ), and BanI/RsaI (for $A B C B 12677 \mathrm{G}>\mathrm{T} / \mathrm{A}$ ), which can recognize and cleave specific sequences. These digested fragments were separated by electrophoresis in $2.5 \%$ agarose gel, and were visualized under ultraviolet light after staining the gel with ethidium bromide for $30 \mathrm{~min}$.

\subsubsection{Identification of CYP2D6 Alleles}

Polymorphisms $\left({ }^{*} 1\right.$ and $\left.{ }^{*} 10\right)$ in the CYP2D6 gene of individuals were determined using DNA sequencing analysis. The primers were designed and prepared using the primer3 software. The PCR was performed in $20 \mu \mathrm{L}$ reaction mixture including $1 \mu \mathrm{L}$ extracted DNA, $1 \mu \mathrm{L}$ of 10 pmol of each primer (forward and reverse), and $17 \mu \mathrm{L}$ autoclaved distilled water. The PCR program was composed of an initial denaturation at $94{ }^{\circ} \mathrm{C}$ for $3 \mathrm{~min}$ followed by 35 cycles of denaturation at $94{ }^{\circ} \mathrm{C}$ for $20 \mathrm{~s}$, annealing for at $62{ }^{\circ} \mathrm{C} 30 \mathrm{~s}$, and extension at $72{ }^{\circ} \mathrm{C}$ for $20 \mathrm{~min}$. A final extension step was conducted at $72{ }^{\circ} \mathrm{C}$ for $5 \mathrm{~min}$. The PCR products were then analyzed by direct sequencing using the ABI PRISIM BigDye Terminator Cycle Sequencing Kit and an ABI Prism 3100 Genetic Analyzer (Applied Biosystems, Foster City, CA, USA).

\subsubsection{Identification of OCT2 808G $>\mathrm{T}$}

Candidate SNP $(808 \mathrm{G}>\mathrm{T})$ in the OCT2 gene was genotyped using pyrosequencing analysis. Each primer was prepared according to the variation of allele. Forward primer of $5^{\prime}$-CGGAGAACAGT GGGGATTTTTTAC-3' , reverse primer of 5'-CACGTAATTCCTTCCGTCTGAAGA-3' , and sequencing primer of 5'-GGTGGTTGCAGTTCACA-3' were used for OCT2 808G > T genotype. Forward primer has a $5^{\prime}$ biotin triethylene glycol label necessary for post PCR processing. PCR was performed in $20 \mu \mathrm{L}$ reaction mixture including $1 \mu \mathrm{L}$ extracted DNA, $1 \mu \mathrm{L}$ of 10 pmol each primer (forward and reverse), and $17 \mu \mathrm{L}$ autoclaved distilled water. The PCR program comprised an initial denaturation at $94{ }^{\circ} \mathrm{C}$ for $5 \mathrm{~min}$ followed by 45 cycles of denaturation at $94{ }^{\circ} \mathrm{C}$ for $20 \mathrm{~s}$, annealing at $52.1^{\circ} \mathrm{C}$ for $30 \mathrm{~s}$, and extension at $72{ }^{\circ} \mathrm{C}$ for $20 \mathrm{~s}$. A final extension step was performed at $72{ }^{\circ} \mathrm{C}$ for $5 \mathrm{~min}$. The biotinylated PCR products were immobilized on streptavidin-coated Sepharose beads (Amersham Biosciences, Uppsala, Sweden). A total of $37 \mu \mathrm{L}$ of binding buffer $(10 \mathrm{mM}$ Tris $\mathrm{HCl}, 2 \mathrm{M}$ sodium chloride, $1 \mathrm{mM}$ EDTA, $0.1 \%$ Tween 20, pH 7.6; Pyrosequencing AB, Uppsala, Sweden), $3 \mu \mathrm{L}$ of streptavidin-coated Sepharose beads, and $20 \mu \mathrm{L}$ of water were added to $20 \mu \mathrm{L}$ PCR product; then, the solution was vigorously shaken for $10 \mathrm{~min}$ at room temperature. A 96 pin magnetic tool (Pyrosequencing AB, Uppsala, Sweden) was used to transfer up 
to 96 samples at a time to solutions as follows. The beads with bound template were first transferred to $70 \%$ ethanol solution and $0.2 \mathrm{~N}$ sodium hydroxide solution, then to $1 \mathrm{X}$ washing buffer (Pyrosequencing $\mathrm{AB}$, Uppsala, Sweden), and finally into a solution of $1 \mathrm{X}$ annealing buffer ( $20 \mathrm{mM}$ Tris acetate, $2 \mathrm{mM}$ magnesium acetate, $\mathrm{pH}$ 7.6), including the appropriate sequencing primer of 10 pmol. Lastly, this mixture was heated for $1 \mathrm{~min}$ to $95^{\circ} \mathrm{C}$ and then cooled to $50^{\circ} \mathrm{C}$ and incubated at room temperature for at least $5 \mathrm{~min}$ to bind the sequencing primer to the template. After template preparation, a 96-well plate including the samples was loaded into the instrument (PSQ 96MA; Pyrosequencing AB, Uppsala, Sweden) along with the optimal reagents (Pyro Gold; Biotage AB, Uppsala, Sweden). This instrument sequences the templates by dispensing reagents and deoxynucleotide triphosphates in a user-defined order, achieving real-time sequencing by synthesis in an automated fashion. This is achieved by creating and monitoring an enzyme cascade initiated by nucleotide incorporation that produces light emission. Pyrosequencing data were obtained by using Peak Height Determination Software v2.1 (Pyrosequencing AB, Uppsala, Sweden).

\subsubsection{Identification of PEPT1 1287G $>C$ (in Exon 16)}

Candidate SNP $(1287 \mathrm{G}>\mathrm{C})$ in the PEPT1 gene were genotyped by using PCR-RFLP. Each primer was prepared according to the variation of allele. Forward primer of $5^{\prime}$-CCCTTGTCAGGGTTAAGATGA-3' and reverse primer of $5^{\prime}$-GCTTCTCTAAATCCTATTATAACAGGG-3' were used for PEPT1 1287G>C genotypes. PCR was performed in $20 \mu \mathrm{L}$ reaction mixture including $1 \mu \mathrm{L}$ extracted DNA, $1 \mu \mathrm{L}$ of 10 pmol each primer (forward and reverse), and $17 \mu \mathrm{L}$ autoclaved distilled water. The PCR program comprised of an initial denaturation at $95{ }^{\circ} \mathrm{C}$ for 5 min followed by 35 cycles of denaturation at $95{ }^{\circ} \mathrm{C}$ for $20 \mathrm{~s}$, annealing for at $54.5^{\circ} \mathrm{C} 30 \mathrm{~s}$, and an extension at $72{ }^{\circ} \mathrm{C}$ for $20 \mathrm{~s}$. The final extension step was performed at $72{ }^{\circ} \mathrm{C}$ for $5 \mathrm{~min}$. DNA fragments amplified by PCR were reacted at $37^{\circ} \mathrm{C}$ for $1 \mathrm{~h}$ with restriction enzyme Sau961, which can recognize and cleave specific sequences. The digested fragments were separated by electrophoresis in $2.5 \%$ agarose gel, and were visualized under ultraviolet light after staining the gel with ethidium bromide for $30 \mathrm{~min}$.

\subsection{Determination of Plasma Tiropramide Concentrations}

Plasma concentrations of tiropramide were determined using a validated column-switching semi-micro high-performance liquid chromatography (HPLC) method based on a previous study [12].

\subsubsection{Chromatographic Conditions}

The analytical system consisted of the Nanospace SI-2 series (Shiseido, Tokyo, Japan) with an ultraviolet-visible (UV-VIS) detector 3002, two 3001 pumps, a 3014 column oven, a high pressure six-way switching valve 3012, a 3010 degasser, and a 3023 autosampler. The system operation and signal processing were operated by Syscon (Shiseido, Tokyo, Japan). The columns used in this on-line extraction system include an analytical column (Capcell Pak $C_{18}$ UG120, $150 \times 1.5 \mathrm{~mm}$ I.D. Shiseido), a pre-column (Capcell Pak MF Ph-1, $10 \times 4 \mathrm{~mm}$ I.D. $5 \mu \mathrm{m}$ Shiseido), and an enrichment column (Capcell Pak $\mathrm{C}_{18}$ UG120, $35 \times 2 \mathrm{~mm}$ I.D. Shiseido). The mobile phase for primary separation of tiropramide in the pre-column and concentration in the enrichment column was phosphate buffer ( $50 \mathrm{mM}, \mathrm{pH} 7.0)$-acetonitrile $(88 / 12, \mathrm{v} / \mathrm{v})$ with a flow rate of $0.5 \mathrm{~mL} / \mathrm{min}$. The mobile phase for analytical column was phosphoric acid-phosphate buffer $(50 \mathrm{mM}, \mathrm{pH} 7.0)$-acetonitrile $(0.04 / 59.96 / 40, \mathrm{v} / \mathrm{v} / \mathrm{v})$ with a flow rate of $0.1 \mathrm{~mL} / \mathrm{min}$. All the columns were maintained at $25-30{ }^{\circ} \mathrm{C}$. The quantification was performed at $230 \mathrm{~nm}$ wavelength. The peak with the retention time of tiropramide was verified using a photodiode array detector (2017 Diode Array, Shiseido, Tokyo, Japan).

\subsubsection{Analytical Procedures}

The performance of column-switching semi-micro HPLC consists of three steps, as follows: sample loading and primary separation, enrichment of analyte fraction, and chromatographic separation. When the column-switching valve was at the precolumn inlet position, an aliquot of filtered (by $0.22 \mu \mathrm{m}$, 
Millex-GV syringe filter unit, Millipore, Burlington, MA, USA) plasma sample ( $80 \mu \mathrm{L})$ was loaded to the pre-column, and a primary separation of tiropramide from plasma proteins was conducted by using phosphate buffer $(50 \mathrm{mM}, \mathrm{pH} 7.0)$-acetonitrile (88/12, v/v). Subsequently, the valve was switched to the enrichment column inlet position, and the tiropramide fraction was eluted from the pre-column and concentrated in the enrichment column by phosphate buffer ( $50 \mathrm{mM}, \mathrm{pH} 7.0)$-acetonitrile (88/12, $\mathrm{v} / \mathrm{v})$. Afterwards, the valve was switched to analytical column inlet position, and tiropramide was finally isolated and quantified by phosphoric acid-phosphate buffer (50 mM, pH 7.0)-acetonitrile $(0.04 / 59.96 / 40, \mathrm{v} / \mathrm{v} / \mathrm{v})$.

\subsection{Pharmacokinetic Analysis}

Basic PK parameters of tiropramide were obtained from non-compartmental analysis (NCA) through the Phoenix-WinNonlin (8.1 version, Pharsight, Certara Inc., Princeton, NJ, USA) program. Peak plasma concentration $\left(C_{\max }\right)$ and the time to reach $C_{\max }\left(T_{\max }\right)$ were individually determined using plasma concentration-time curve. The area under the curve $\left(\mathrm{AUC}_{0-\infty}\right)$ was calculated as the sum of $\mathrm{AUC}_{0-\mathrm{t}}$ and $\mathrm{C}_{\text {last }} / \mathrm{k}$, where $\mathrm{C}_{\text {last }}$ is the final measured concentration and $\mathrm{k}$ is the elimination rate constant at terminal phase. $\mathrm{AUC}_{0-\mathrm{t}}$ was calculated using a linear trapezoidal rule from 0 to $\mathrm{t}$ (as 24$) \mathrm{h}$ after administration. The half-life $\left(\mathrm{t}_{1 / 2}\right)$ was calculated as $0.693 / \mathrm{k}$, and the volume of the distribution $\left(\mathrm{V}_{\mathrm{d}} / \mathrm{F}\right)$ was calculated as dose $/ \mathrm{k} \cdot \mathrm{AUC}_{0-\infty}$. The clearance $(\mathrm{CL} / \mathrm{F})$ was calculated by dividing the dose of tiropramide by $\mathrm{AUC}_{0-\infty}$, where $\mathrm{F}$ is the bioavailability of oral administration. All $\mathrm{PK}$ parameter values were calculated as mean $\pm \mathrm{SD}$, and the statistical differences in the group parameters (according to genotype) were confirmed by the analysis of variance (ANOVA) through the Statistical Package for the Social Sciences (SPSS) program (23 version, IBM). A $p$-value $<0.05$ was established as being statistically significant.

\subsection{Model Development}

PPK analysis was conducted with a non-linear mixed effects model (NLME) approach through the Phoenix NLME (8.1 version, Pharsight, Certara Inc., Princeton, NJ, USA) program. In addition, PPK model development was performed in the first order conditional estimates method with extended least squares (FOCE-ELS) estimation (with $\eta-\varepsilon$ interaction).

As the first step of PPK modeling, data were fitted to two or one compartment disposition models with first order elimination and absorption kinetics without or with absorption lag-time for determining the structural base model (without covariates). In addition, a multiple transit model with a compartment added to the absorption phase was evaluated to establish the structural base model. The final selection of structural base model was performed by the statistical significance between models using goodness-of-fit (GOF) plots, twice the negative log likelihood (-2LL), and Akaike's information criterion (AIC). The initial values for the parameters used in this process were obtained and referenced using NCA and classic compartment models. As a result, the basic PK parameters were as follows: clearance for the central compartment $(\mathrm{CL})$, absorption lag time $\left(\mathrm{T}_{\mathrm{lag}}\right)$, volume of distribution for the central compartment $(\mathrm{V})$, first oral absorption rate constant $\left(\mathrm{K}_{\mathrm{a} 1}\right)$, and second oral absorption rate constant $\left(\mathrm{K}_{\mathrm{a} 2}\right)$.

The residual variability was determined to additive error model in log transformed (plasma concentration) data, as shown in the following equation: $C_{o b s, i j}=C_{\text {pred,ij }} \cdot \exp \left(\varepsilon_{\mathrm{ij}}\right)$, where $\varepsilon_{\mathrm{ij}}$ is the intra-subject variability (including model misspecification and assay error) with mean 0 and variance $\sigma^{2}$, and $C_{\text {pred,ij }}$ and $C_{o b s, i j}$ are the jth predicted and observed plasma concentrations in the ith subject, respectively.

The inter-individual variability (IIV) in PK parameters of tiropramide was evaluated by using an exponential error model, as shown in the following equation: $P_{i}=P_{t v} \cdot \exp \left(\eta_{i}\right)$, where $\eta_{i}$ is the random variable for the ith individual, which was normally distributed with mean 0 and variance $\omega^{2} ; P_{i}$ is the parameter value of the ith individual, and $\mathrm{P}_{\mathrm{tv}}$ is the typical value of the population parameter. 
As a second step of PPK modeling, candidate covariates (including demographic and genetic information) screened during this study were considered in reflecting the structural base model to account for PK diversity of tiropramide in the population. Height, body weight, age, BMI, BSA, creatinine, albumin, AST, ALT, ALP, creatinine clearance, and total protein were used as demographic candidate covariates. Here, BMI was determined by using the metric unit system [13]. BSA was determined on the basis of the Mosteller equation [14]. Creatinine clearance was determined on the basis of the Cockcroft-Gault equation [15]. There were also $A B C B 1$ 1236C $>\mathrm{T}, A B C B 12677 \mathrm{G}>\mathrm{T} / \mathrm{A}$, $A B C B 13435 C>\mathrm{T}, C Y P 2 D 6\left({ }^{*} 1\right.$ and $\left.{ }^{*} 10\right)$, OCT2 $808 \mathrm{G}>\mathrm{T}$, and PEPT1 1287G $>C$ as genetic candidate covariates. To confirm the correlation between covariates and PK parameters, these potential covariates were plotted against individual post hoc parameters. In addition, the covariates were divided into categorical and continuous types in order to reflect the identified (correlation with PK parameters) candidate covariates in the PK parameters of the model. Continuous covariates (mainly demographic candidate covariates) were normalized by median values (of observed values). On the other hand, categorical covariates (mainly genetic candidate covariates) were reflected as index variables in the model. The effects of each covariate were confirmed using exponential, power, or additive options. By stepwise backward elimination and forward addition procedure, the covariates were included or eliminated. By change in the objective function value (OFV), the inclusion of covariates was determined. Covariates corresponding to a decrease in the OFV value greater than $3.84(p<0.05)$ were included in the base model (in the forward addition procedure). In addition, covariates corresponding to the case where the decrease in OFV value was greater than $6.63(p<0.01)$ through the backward elimination process were not removed from the model and were included.

\subsection{Model Evaluation}

The final established models (in this study) were verified and evaluated both visually and numerically. To evaluate the model, visual predictive check (VPC), bootstrapping, and goodness-of-fit (including distribution of residuals) analyses were used. The goodness-of-fit was confirmed by using diagnostic scatter plots as follows: (a) population-predicted concentrations (PRED) versus observed (DV), (b) individual-predicted concentrations (IPRED) versus DV, (c) PRED versus conditional weighted residuals (CWRES), (d) time (IVAR) versus CWRES, and (e) quantile-quantile plot of the components of CWRES.

By using non-parametric bootstrap analysis, the stability of the final model was confirmed, and the bootstrap option of Phoenix NLME was used. A total of 1000 replicates were generated by the repeated random sampling with replacement from the original dataset. The estimated parameter values, such as the standard errors (SE; including confidence intervals) and medians from the bootstrap procedure, were compared with those estimated from the original dataset.

By using the VPC option of Phoenix NLME, VPCs of the final established models were performed. The time-DV concentration data were graphically superimposed on the median values and the 5th and 95th percentiles of the time-simulated concentration profiles. If the DV concentration data were approximately distributed within the 95th and 5th prediction interval, the model was expected to be precise. Normalized prediction distribution error (NPDE) was used to evaluate the predictive performance of the model on the basis of a Monte Carlo simulation with the R package [16]. NPDE results were summarized graphically using (1) quantile-quantile plot of the NPDE, (2) a histogram of the NPDE, (3) scatterplot of NPDE vs. time, and (4) scatterplot of NPDE vs. PRED. If the predictive performance is satisfied, the NPDE will follow a normal distribution (Shapiro-Wilk test) with a mean value of zero ( $t$-test) and a variance of one (Fisher's test). 


\section{Results}

\subsection{Study Design and Demographic Analysis}

The bioequivalence data (from reference formulation) collected from 24 healthy Korean males were used in this PK study for tiropramide. For the PK modelling, a total of 288 tiropramide plasma concentrations were available. There was complete information on height, age, and body weight for the 24 participants. Additionally, we successfully collected information on the total proteins, albumin, creatinine, AST, ALT, ALP, and the creatinine clearance levels of each participant, according to the method described above (Section 2.2). The related demographic information about the participants are shown in Table 1.

Table 1. Demographic information of the studied subjects $(n=24)$.

\begin{tabular}{|c|c|c|}
\hline Physicochemical & Median (Range) & Mean \pm SD \\
\hline Age (year) & $23(19-29)$ & $22.96 \pm 2.61$ \\
\hline Weight (kg) & $66.8(52.5-82.8)$ & $67.60 \pm 7.28$ \\
\hline Height $(\mathrm{cm})$ & $171.45(164.3-185.4)$ & $172.59 \pm 5.85$ \\
\hline $\operatorname{BSA}\left(\mathrm{m}^{2}\right) *$ & $1.80(1.58-1.97)$ & $1.80 \pm 0.11$ \\
\hline $\operatorname{BMI}\left(\mathrm{kg} / \mathrm{m}^{2}\right)^{* *}$ & $22.63(17.89-29.06)$ & $22.74 \pm 2.72$ \\
\hline Albumin (g/dL) & $4.6(4.2-5.4)$ & $4.64 \pm 0.27$ \\
\hline Total proteins $(\mathrm{g} / \mathrm{dL})$ & $7.6(6.7-8.3)$ & $7.59 \pm 0.41$ \\
\hline ALT $(\mathrm{U} / \mathrm{L})$ & $20.5(8-55)$ & $22.29 \pm 11.67$ \\
\hline AST (U/L) & $20(10-32)$ & $20.88 \pm 5.81$ \\
\hline $\operatorname{ALP}(\mathrm{U} / \mathrm{L})$ & $76(49-126)$ & $81.83 \pm 20.66$ \\
\hline Creatinine clearance $(\mathrm{mL} / \mathrm{min}){ }^{* * *}$ & $118.49(91.78-159.77)$ & $122.88 \pm 22.25$ \\
\hline Creatinine (mg/dL) & $0.9(0.6-1.1)$ & $0.91 \pm 0.13$ \\
\hline
\end{tabular}

* Body surface area (BSA) was determined on the basis of the Monsteller equation as follows: $\sqrt{(\text { height }(\mathrm{cm}) \times \text { weight }(\mathrm{kg}) / 3600)}$; ** body mass index (BMI) was calculated as follows: body weight $(\mathrm{kg}) / \mathrm{height}^{2}$ $\left(\mathrm{m}^{2}\right)$; ${ }^{* * *}$ creatinine clearance was determined on the basis of the Cockcroft-Gault equation as follows: [(140-age) $\times$ body weight $(\mathrm{kg})] /[$ serum creatinine $(\mathrm{mg} / \mathrm{dL}) \times 72]$.

\subsection{Genetic Analysis}

Genotyping was performed on all 24 individuals who participated in this study. The analyzed genotypes were $A B C B 1\left(1236 \mathrm{C}>\mathrm{T}, 2677 \mathrm{G}>\mathrm{T} / \mathrm{A}\right.$, and 3435C > T), CYP2D6 ( ${ }^{*} 1$ and *10), OCT2 (808G $\left.>\mathrm{T}\right)$, and PEPT1 $(1287 \mathrm{G}>\mathrm{C})$ genes. The results are presented in Table 2 . The $A B C B 11236 \mathrm{C}>\mathrm{T}$ genotyping revealed that $6(25.00 \%)$ subjects had the mutant type (TT), $13(54.17 \%)$ subjects had the heterozygous type (CT), and 5 (20.83\%) subjects had the homozygous wild type (CC). ABCB1 2677G>T/A genotyping revealed that eight (33.33\%) subjects had the mutant type (TT or AT or TA or AA), nine (37.50\%) subjects had the heterozygous type (GT or GA), and seven $(29.17 \%)$ subjects had the homozygous wild type (GG). $A B C B 13435 \mathrm{C}>\mathrm{T}$ genotyping revealed that $3(12.50 \%)$ subjects had the mutant type (TT), $12(50.00 \%)$ subjects had the heterozygous type (CT), and $9(37.50 \%)$ subjects had the homozygous wild type (CC). CYP2D6 genotyping revealed that $6(25.00 \%)$ subjects had the homozygous *10 allele $\left({ }^{*} 10 /{ }^{*} 10\right), 14(58.33 \%)$ subjects had the heterozygous $* 10$ allele $\left({ }^{*} 1 /{ }^{*} 10\right)$, and $4(16.67 \%)$ subjects had the homozygous ${ }^{*} 1$ allele $\left({ }^{*} 1 /{ }^{*} 1\right)$. CYP2D $6 * 2,{ }^{*} 4, * 5,{ }^{*} 14 \mathrm{~A} / \mathrm{B},{ }^{*} 36$, and ${ }^{*} 47$ alleles were not detected in any of the subjects of this study. We classified the CYP2D6 genotypes into three groups to investigate the impact of CYP2D6 genotypes on the PKs of tiropramide as follows: extensive metabolizers (EMs) $\left({ }^{*} 1 /{ }^{*} 1\right)$, heterozygous intermediate metabolizers (IMs) $\left({ }^{*} 1 /{ }^{*} 10\right)$, and homozygous IMs $\left({ }^{*} 10 /{ }^{*} 10\right)$, on the basis of the reports of the difference in CYP2D6 enzyme activity according to CYP2D6 genotypes $[9,17]$. OCT2 808G > T genotyping revealed that 8 (33.33\%) subjects had the heterozygous type (GT) and 16 $(66.67 \%)$ subjects had the homozygous type (GG). PEPT1 1287G>C genotyping revealed that $3(12.50 \%)$ subjects had the mutant type (CC), 2 (8.33\%) subjects had the heterozygous type (GC), and 19 (79.17\%) subjects had the homozygous wild type (GG). 
Table 2. Genetic information of the studied subjects $(n=24)$.

\begin{tabular}{ccc}
\hline Genotypes & & No. (Frequency) \\
\hline$A B C B 1$ & & $5(20.83 \%)$ \\
1236C $>$ T (exon 12) & CC & $13(54.17 \%)$ \\
& CT & $6(25.00 \%)$ \\
2677G $>$ T/A (exon 21) & TT & $7(29.17 \%)$ \\
& GG, GA & $9(37.50 \%)$ \\
$3435 \mathrm{C}>$ T (exon 26) & TT, AT, TA, AA & $8(33.33 \%)$ \\
& CC & $9(37.50 \%)$ \\
CYP2D6 & CT & $12(50.00 \%)$ \\
& TT & $3(12.50 \%)$ \\
OCT2 & ${ }^{*}{ }^{*} 1$ & $4(16.67 \%)$ \\
808G $>$ T & ${ }^{*} 10$ & $14(58.33 \%)$ \\
& & $6(25.00 \%)$ \\
PEPT1 & GG & $16(66.67 \%)$ \\
$1287 \mathrm{G}>$ C (exon 16) & GT & $8(33.33 \%)$ \\
& GG & $19(79.17 \%)$ \\
& GC & $2(8.33 \%)$ \\
& CC & $3(12.50 \%)$ \\
\hline
\end{tabular}

\subsection{Determination of Plasma Tiropramide Concentrations}

After the oral administration of a $100 \mathrm{mg}$ dose, plasma concentrations of tiropramide were determined by a column-switching semi-micro HPLC method (as mentioned in Section 2.4). This method analyzed tiropramide at a run time of 25 min per sample, enabling PK studies on tiropramide. The linearity of calibration curve for tiropramide was excellent $\left(r^{2}=0.99\right)$ in human plasma, ranging from 2 to $500 \mathrm{ng} / \mathrm{mL}$. Moreover, the calculation formula of the calibration curve was as follows: $y=384.51 x+320.45(p<0.01)$, where $y$ is the peak area of tiropramide and $x$ is the concentration $(\mathrm{ng} / \mathrm{mL})$ of the tiropramide. In addition, the lower limit of quantitation (LLOQ) for tiropramide was as low as $2 \mathrm{ng} / \mathrm{mL}$, and was sufficient for PK studies after the oral administration of tiropramide tablet to humans. This assay has been validated for specificity, accuracy, precision, and sensitivity in order to be applied to accurate PK studies. There were no significant interferences derived from system or endogenous substances peaks, and we confirmed the identical tiropramide peak spectrum with the diode array detector. Intra-batch $(n=5)$ accuracies for tiropramide ranged from $100.70 \%$ to $113.50 \%$ with precision (coefficient of variation, CV) of $<13.57 \%$. Inter-batch $(n=5)$ accuracies for tiropramide ranged from $98.00 \%$ to $111.42 \%$ with precision (CV) of $<9.23 \%$.

\subsection{Pharmacokinetic (NCA) Analysis}

The observed plasma concentration-time profiles of tiropramide in the 24 subjects after oral administration of the $100 \mathrm{mg}$ dose are presented in Figure 1.

In most individuals, the concentration of tiropramide in blood was measured up to $12 \mathrm{~h}$ after dosing. The PK parameters of tiropramide according to the genotypes ( $A B C B 1$ 1236C $>\mathrm{T}, A B C B 1$ 2677G > T/A, ABCB1 3435C > T, CYP2D6, OCT2 808G > T, and PEPT1 1287G >C) calculated by NCA are presented in Table 3. According to the NCA results for each genotype, the diversity of PK parameters in each group was not significant $(p>0.05)$. Although the higher mean $\mathrm{AUC}_{0-\mathrm{t}}, \mathrm{AUC}_{0-\infty}$, and $\mathrm{C}_{\max }$ values but lower mean $\mathrm{CL} / \mathrm{F}$ values were calculated in the mutant type group (TT) than in the wild homozygous type groups (CC) in the $A B C B 11236 C>\mathrm{T}$ gene, this was not statistically significant considering the high SD. In the CYP2D6 gene, higher mean $A U C_{0-t}, A C_{0-\infty}$, and $C_{\max }$ values were calculated for IMs $\left({ }^{*} 1 /{ }^{*} 10\right.$ and $\left.{ }^{*} 10 /{ }^{*} 10\right)$ than EMs $\left({ }^{*} 1 /{ }^{*} 1\right)$, but this was also not statistically significant considering the high $\mathrm{SD}$. In addition, although the higher mean $\mathrm{C}_{\max }, \mathrm{AUC}_{0-\mathrm{t}}$, and $\mathrm{AUC}_{0-\infty}$ values 
and lower mean CL/F value were calculated in wild homozygous type groups (GG) than in mutant type group (CC) in the PEPT1 $1287 \mathrm{G}>\mathrm{C}$ gene, this was not statistically significant considering the high SD. The $\mathrm{AUC}_{0-\mathrm{t}}, \mathrm{AUC}_{0-\infty}, \mathrm{C}_{\max }$, half-life, and $\mathrm{T}_{\max }$ values calculated by the NCA analysis of tiropramide were $254.31 \pm 197.38 \mathrm{~h} \cdot \mathrm{ng} / \mathrm{mL}, 280.34 \pm 199.96 \mathrm{~h} \cdot \mathrm{ng} / \mathrm{mL}, 69.07 \pm 59.74 \mathrm{ng} / \mathrm{mL}, 3.41 \pm 1.99 \mathrm{~h}$, and $1.74 \pm 0.63 \mathrm{~h}$, respectively.
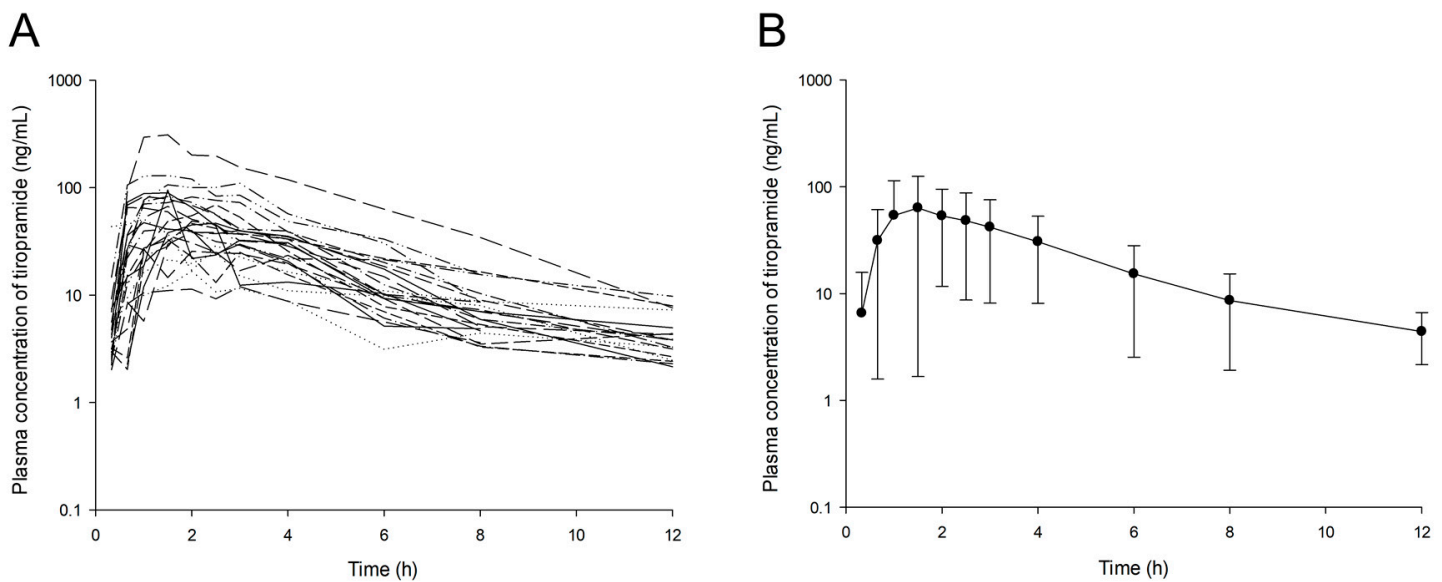

Figure 1. Log-transformed plasma concentration-time profiles of tiropramide in 24 subjects (A) and the mean curves $(\mathbf{B})$. The vertical bars represent standard deviation of the mean.

Table 3. Pharmacokinetic parameters of tiropramide after a single oral administration of a $100 \mathrm{mg}$ tiropramide tablet according to the genotypes (mean $\pm \mathrm{SD}, n=24$ ).

\begin{tabular}{|c|c|c|c|c|c|c|c|}
\hline \multicolumn{2}{|c|}{ Genotypes } & \multirow[t]{2}{*}{$\begin{array}{l}\text { Half-Life } \\
(\mathrm{h}-1)\end{array}$} & \multirow[t]{2}{*}{ Tmax (h) } & \multirow[t]{2}{*}{$\mathrm{Cmax}(\mathrm{ng} / \mathrm{mL})$} & \multirow[t]{2}{*}{$\begin{array}{c}\text { AUC0-t } \\
\text { (h.ng/mL) }\end{array}$} & \multirow[t]{2}{*}{ 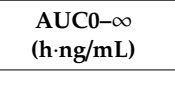 } & \multirow[t]{2}{*}{$\mathrm{CL} / \mathrm{F}(\mathrm{L} / \mathrm{h})$} \\
\hline$A B C B 1$ & & & & & & & \\
\hline \multirow[t]{3}{*}{$1236 \mathrm{C}>\mathrm{T}$} & $\mathrm{CC}(n=5)$ & $2.91 \pm 1.42$ & $1.90 \pm 0.42$ & $104.56 \pm 117.25$ & $394.51 \pm 376.32$ & $419.54 \pm 376.69$ & $380.72 \pm 246.10$ \\
\hline & $\mathrm{CT}(n=13)$ & $3.80 \pm 2.41$ & $1.67 \pm 0.70$ & $49.06 \pm 23.81$ & $182.00 \pm 60.62$ & $209.85 \pm 72.09$ & $551.43 \pm 263.69$ \\
\hline & $\mathrm{TT}(n=6)$ & $2.99 \pm 1.36$ & $1.75 \pm 0.69$ & $82.83 \pm 39.09$ & $293.01 \pm 149.02$ & $317.08 \pm 154.99$ & $419.44 \pm 292.77$ \\
\hline \multicolumn{8}{|l|}{$A B C B 1$} \\
\hline \multirow[t]{3}{*}{$2677 \mathrm{G}>\mathrm{T} / \mathrm{A}$} & GG $(n=7)$ & $3.86 \pm 3.11$ & $1.38 \pm 0.52$ & $52.88 \pm 15.94$ & $214.50 \pm 69.45$ & $247.94 \pm 76.58$ & $439.10 \pm 136.89$ \\
\hline & GT $(n=9)$ & $2.77 \pm 0.89$ & $2.06 \pm 0.73$ & $88.92 \pm 89.16$ & $323.04 \pm 294.51$ & $339.44 \pm 296.97$ & $481.39 \pm 359.30$ \\
\hline & $\begin{array}{c}\text { TT, AT, TA, AA } \\
(n=8)\end{array}$ & $3.75 \pm 1.73$ & $1.69 \pm 0.46$ & $60.89 \pm 39.69$ & $210.97 \pm 122.69$ & $242.22 \pm 135.50$ & $522.84 \pm 259.46$ \\
\hline \multicolumn{8}{|l|}{$A B C B 1$} \\
\hline \multirow[t]{3}{*}{$3435 \mathrm{C}>\mathrm{T}$} & $\mathrm{CC}(n=9)$ & $2.82 \pm 1.11$ & $1.52 \pm 0.46$ & $78.29 \pm 88.96$ & $294.77 \pm 291.67$ & $317.13 \pm 293.75$ & $452.72 \pm 201.28$ \\
\hline & $\mathrm{CT}(n=12)$ & $3.44 \pm 1.45$ & $1.92 \pm 0.70$ & $63.79 \pm 38.63$ & $235.35 \pm 131.42$ & $259.88 \pm 136.73$ & $524.94 \pm 338.71$ \\
\hline & $\mathrm{TT}(n=3)$ & $5.10 \pm 4.82$ & $1.67 \pm 0.76$ & $62.51 \pm 23.63$ & $206.48 \pm 14.18$ & $251.82 \pm 44.95$ & $405.08 \pm 67.07$ \\
\hline \multicolumn{8}{|l|}{$C Y P 2 D 6$} \\
\hline & ${ }^{*} 1 /{ }^{*} 1(n=4)$ & $4.74 \pm 4.00$ & $1.25 \pm 0.29$ & $63.24 \pm 23.66$ & $240.38 \pm 75.18$ & $278.97 \pm 67.41$ & $379.92 \pm 118.76$ \\
\hline & $* 1 /{ }^{*} 10(n=14)$ & $3.14 \pm 1.17$ & $1.76 \pm 0.59$ & $66.73 \pm 72.90$ & $258.15 \pm 238.14$ & $280.90 \pm 240.02$ & $484.79 \pm 223.74$ \\
\hline & $* 10 /{ }^{*} 10(n=6)$ & $3.17 \pm 1.84$ & $2.00 \pm 0.77$ & $78.41 \pm 45.97$ & $253.49 \pm 168.34$ & $279.97 \pm 177.22$ & $547.04 \pm 420.10$ \\
\hline \multicolumn{8}{|l|}{ OCT2 } \\
\hline \multirow[t]{2}{*}{$808 \mathrm{G}>\mathrm{T}$} & GG $(n=16)$ & $3.62 \pm 2.29$ & $1.51 \pm 0.53$ & $60.42 \pm 29.24$ & $218.24 \pm 89.40$ & $247.77 \pm 99.03$ & $459.49 \pm 166.01$ \\
\hline & GT $(n=8)$ & $3.00 \pm 1.20$ & $2.19 \pm 0.59$ & $86.37 \pm 96.84$ & $325.60 \pm 319.70$ & $345.50 \pm 321.06$ & $529.63 \pm 414.56$ \\
\hline \multicolumn{8}{|l|}{ PEPT1 } \\
\hline \multirow[t]{3}{*}{$1287 \mathrm{G}>\mathrm{C}$} & GG $(n=19)$ & $3.07 \pm 1.38$ & $1.82 \pm 0.65$ & $62.40 \pm 32.14$ & $226.40 \pm 109.97$ & $248.21 \pm 115.65$ & $506.33 \pm 278.61$ \\
\hline & $\mathrm{GC}(n=2)$ & $6.36 \pm 6.07$ & $1.25 \pm 0.35$ & $181.48 \pm 184.26$ & $621.48 \pm 609.37$ & $688.85 \pm 546.19$ & $211.72 \pm 167.87$ \\
\hline & $\mathrm{CC}(n=3)$ & $3.63 \pm 0.41$ & $1.50 \pm 0.50$ & $36.36 \pm 9.98$ & $183.99 \pm 65.49$ & $211.54 \pm 80.59$ & $515.08 \pm 168.25$ \\
\hline
\end{tabular}

\subsection{Population Pharmacokinetic Model Development}

By a one-compartment disposition model with first order elimination and absorption with an absorption lag time, the plasma concentrations of tiropramide were best expressed. Considering the lag time, the numerical values (such as -2LL and AIC) of the model evaluation and graphical data fitting were more improved than otherwise. Although we tried a two-compartment model, it did not show an improved fit when compared with the one-compartment model. In other words, there was a problem (fail to model fit) in fitting the two-compartment model for some individuals, but in the one-compartment model, all individuals were fitted properly. In addition, the -2LL and 
AIC values significantly decreased in the multiple (two) transit absorption compartment model in which the additional absorption phase was added to the one-compartment model. However, from two or more transit phases of absorption, there was no significant decrease in the -2LL and AIC values (with increasing number of parameters). As a result, the multiple (two) transit absorption phase-one compartment model with an absorption lag time was selected as the base structure model for tiropramide. The model was parameterized in terms of $\mathrm{V} / \mathrm{F}, \mathrm{T}_{\mathrm{lag}}, \mathrm{CL} / \mathrm{F}, \mathrm{K}_{\mathrm{a} 1}$, and $\mathrm{K}_{\mathrm{a} 2}$. When the lag-time or model transit time was given to $\mathrm{K}_{\mathrm{a} 2}$ in the parameterization of the model, no significant model improvement was found with the increasing number of parameters. Therefore, significant model improvement was found when parameterization with lag-time was carried out only at $K_{a 1}$, and the rate constant of substance transit in the absorption compartment. Figure 2 shows a schematic of the disposition compartment model presented for tiropramide.

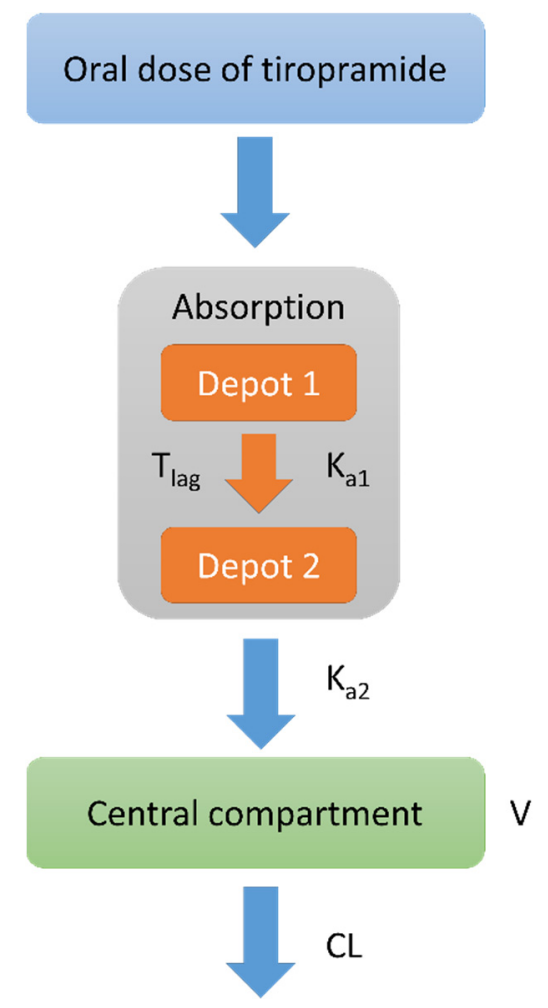

Figure 2. Schematic of tiropramide population pharmacokinetic (PPK) model (two transit absorption phase-one compartment model with an absorption lag time). Depot 1 and 2 represent transit compartments in the absorption phase. $\mathrm{K}_{\mathrm{a} 1}$ refers to the rate constant at which the drug is moved from depot 1 to depot 2. $\mathrm{T}_{\text {lag }}$ refers to the delay time for the drug to move from depot 1 to depot 2 . $\mathrm{K}_{\mathrm{a} 2}$ is the rate constant at which the drug moves from depot 2 to the central compartment. V means the volume of drug distribution in the central compartment, and CL means removal of the drug from the central compartment.

An exponential model was used to describe the IIVs on parameters of $\mathrm{T}_{\mathrm{lag}}, \mathrm{V} / \mathrm{F}, \mathrm{CL} / \mathrm{F}, \mathrm{K}_{\mathrm{a} 1}$, and $\mathrm{K}_{\mathrm{a} 2}$. By applying an additive error model on log-transformed data, the residual variability was explained. Table 4 summarizes the steps for developing a basic structural model of tiropramide.

In order to find the covariates affecting the PK parameters of tiropramide, we analyzed the effects of each covariate on the PK parameters. The final potential covariates were selected on the basis of the graphical exploration between candidate covariates and PK parameters. The influence of each selected candidate covariate on the PK parameters of tiropramide was assessed by incorporating the covariates into an established basic structural model. The evaluation was based on OFV, which means model 
improvement. In this regard, the covariate selection process (according to OFV) to be reflected in the final model of tiropramide is summarized in Table 5.

Table 4. Basic structural model building steps.

\begin{tabular}{|c|c|c|c|c|c|c|c|}
\hline Model & Description & n-Parameter & $-2 L L$ & AIC & $\Delta-2 L L$ & $\Delta \mathrm{AIC}$ & $\begin{array}{l}\text { Compared } \\
\text { with }\end{array}$ \\
\hline & Absorption model & & & & & & \\
\hline 1 & One compartment with first order (no $\mathrm{T}_{\mathrm{lag}}$ ) & 7 & 562.27 & 576.27 & & & \\
\hline 2 & One compartment with the first order (add $\mathrm{T}_{\mathrm{lag}}$ ) & 9 & 508.80 & 526.80 & -53.48 & -49.48 & 1 \\
\hline $3 *$ & $\begin{array}{l}\text { One compartment with the first order (add } \mathrm{T}_{\text {lag }} \\
\text { and additonal absorption transit phase one) }\end{array}$ & 11 & 420.97 & 442.97 & -87.83 & -83.83 & 2 \\
\hline 4 & $\begin{array}{l}\text { One compartment with the first order (add } \mathrm{T}_{\text {lag }} \\
\text { and additonal absorption transit phase two) } \\
\text { Residual error model }\end{array}$ & 13 & 419.84 & 442.11 & -1.13 & -0.86 & 3 \\
\hline $3 *$ & Log additive & 11 & 420.97 & 442.97 & & & \\
\hline 5 & Additive & 11 & 1964.95 & 1986.95 & 1543.98 & 1543.98 & 3 \\
\hline 6 & $\begin{array}{l}\text { Proportional } \\
\text { IIV model }\end{array}$ & 11 & 1860.33 & 1882.33 & 1439.36 & 1439.36 & 3 \\
\hline 7 & Remove IIV $\mathrm{K}_{\mathrm{a} 1}$ & 10 & 428.64 & 448.64 & 7.67 & 5.67 & 3 \\
\hline 8 & Remove IIV $\mathrm{K}_{\mathrm{a} 2}$ & 10 & 428.64 & 448.64 & 7.67 & 5.67 & 3 \\
\hline 9 & Remove IIV $\mathrm{T}_{\text {lag }}^{\mathrm{az}}$ & 10 & 434.18 & 454.18 & 13.21 & 11.21 & 3 \\
\hline 10 & Remove IIV V/F & 10 & 500.86 & 520.86 & 79.89 & 77.89 & 3 \\
\hline 11 & Remove IIV CL/F & 10 & 534.10 & 554.10 & 113.13 & 111.13 & 3 \\
\hline
\end{tabular}

* Selected model.

Table 5. Stepwise search for covariates.

\begin{tabular}{|c|c|c|c|c|c|}
\hline Model & Description & OFV & $\Delta \mathrm{OFV}$ & n-Parameter & Compared with \\
\hline 1 & Base model & 420.97 & & 11 & \\
\hline 2 & Total protein on $\mathrm{CL} / \mathrm{F}$ & 411.72 & -9.25 & 12 & 1 \\
\hline $3 *$ & Total protein on $\mathrm{CL} / \mathrm{F}$ and $\mathrm{V} / \mathrm{F}$ & 402.56 & -9.16 & 13 & 2 \\
\hline 4 & $\begin{array}{c}\text { Total protein on } \mathrm{CL} / \mathrm{F} \text { and } \mathrm{V} / \mathrm{F} \text {, } \\
\text { BMI on } \mathrm{K}_{\mathrm{a} 1}\end{array}$ & 400.61 & -1.95 & 14 & 3 \\
\hline 5 & $\begin{array}{c}\text { Total protein on } \mathrm{CL} / \mathrm{F} \text { and } \mathrm{V} / \mathrm{F} \text {, } \\
\text { PEPT1 }(1287 \mathrm{G}>\mathrm{C}) \text { on } \mathrm{K}_{\mathrm{a} 1}\end{array}$ & 402.57 & 0.01 & 14 & 3 \\
\hline 6 & $\begin{array}{c}\text { Total protein on } \mathrm{CL} / \mathrm{F} \text { and } \mathrm{V} / \mathrm{F} \text {, } \\
\qquad A B C B 1(1236 \mathrm{C}>\mathrm{T}) \text { on } \mathrm{K}_{\mathrm{a} 1}\end{array}$ & 401.63 & -0.93 & 14 & 3 \\
\hline 7 & $\begin{array}{l}\text { Total protein on CL/F and V/F, } \\
\text { CYP2D }\left({ }^{*} 1 \text { and }{ }^{*} 10\right) \text { on } \mathrm{K}_{\mathrm{a} 2}\end{array}$ & 397.15 & -5.42 & 15 & 3 \\
\hline
\end{tabular}

* Selected final model.

There was a significant correlation between the total protein and tiropramide V/F as well as the total protein and tiropramide CL/F. Figure 3 shows the correlation between the final selected covariates and $\mathrm{CL} / \mathrm{F}$ of tiropramide.

A

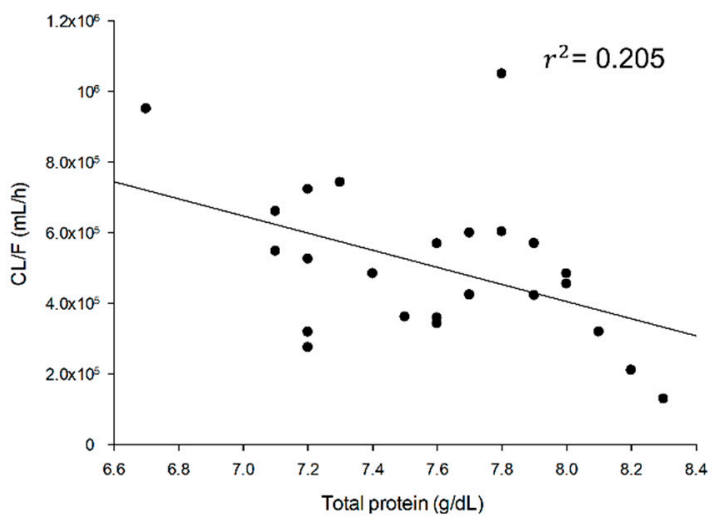

B

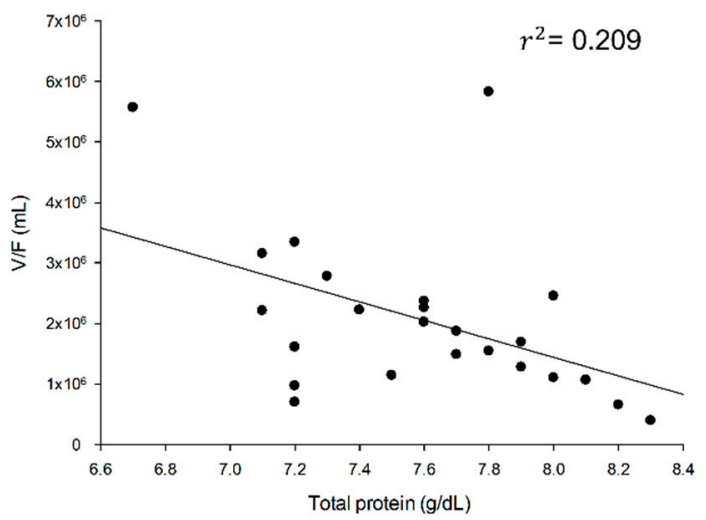

Figure 3. Relationship between subjects' characteristics and individual predicted pharmacokinetic parameters. Clearance (CL/F) of tiropramide according to total protein (A). Volume of distribution $(\mathrm{V} / \mathrm{F})$ of tiropramide according to total protein $(\mathbf{B})$. 
When the correlation between the total protein and CL/F was reflected in the PPK model of tiropramide, the $\triangle \mathrm{OFV}$ was significantly reduced to $-9.25(p<0.05)$. Furthermore, the addition of total protein and V/F correlation to tiropramide PPK model significantly reduced the $\triangle \mathrm{OFV}$ to -9.16 $(p<0.05)$. However, other covariates including BMI, PEPT1 1287G >C, OCT2 808G $>\mathrm{T}, A B C B 1$ 1236C $>\mathrm{T}$, $A B C B 12677 \mathrm{G}>\mathrm{T} / \mathrm{A}, A B C B 13435 \mathrm{C}>\mathrm{T}$, and CYP2D6 ( ${ }^{*} 1$ and $\left.{ }^{*} 10\right)$ had no significant effect on model improvement. Even by applying genetic factors (such as PEPT1 1287G>C, OCT2 808G>T, ABCB1 1236C > T, ABCB1 2677G > T/A, ABCB1 3435C > T, and CYP2D6 ( ${ }^{*} 1$ and $\left.\left.{ }^{*} 10\right)\right)$ alone to the base model, we examined whether they affected $\mathrm{K}_{\mathrm{a} 1}, \mathrm{~K}_{\mathrm{a} 2}, \mathrm{CL} / \mathrm{F}$, and $\mathrm{V} / \mathrm{F}$, but no significant associations were identified. The final model of tiropramide (reflecting the effects of covariates) is expressed as follows:

$$
\begin{gathered}
\mathrm{V} / \mathrm{F}=\mathrm{tvV} / \mathrm{F} \cdot(1+(\text { Totalproteins }-7.6) \cdot \mathrm{dV} / \mathrm{FdTotalproteins}) \cdot \exp \left(\eta_{\mathrm{V}}\right) \\
\mathrm{CL} / \mathrm{F}=\mathrm{tvCL} / \mathrm{F} \cdot\left(1+(\text { Totalproteins-7.6) } \cdot \mathrm{dCL} / \text { FdTotalproteins }) \cdot \exp \left(\eta_{\mathrm{CL}}\right)\right. \\
\mathrm{T}_{\text {lag }}=\mathrm{tvT}_{\text {lag }} \cdot \exp \left(\eta_{\mathrm{Tlag}}\right) \\
\mathrm{K}_{\mathrm{a} 1}=\mathrm{tvK}_{\mathrm{a} 1} \cdot \exp \left(\eta_{\mathrm{Ka} 1}\right) \\
\mathrm{K}_{\mathrm{a} 2}=\mathrm{tvK}_{\mathrm{a} 2} \cdot \exp \left(\eta_{\mathrm{Ka} 2}\right)
\end{gathered}
$$

Population estimates of tiropramide were $466,711 \mathrm{~mL} / \mathrm{h}$ for CL/F and 1,889,250 mL for V/F. CL/F and V/F values by NCA were $482,567 \pm 267,433 \mathrm{~mL} / \mathrm{h}$ and 2,386,871 $\pm 1,699,847 \mathrm{~mL}$, respectively. As a result, the $\mathrm{CL} / \mathrm{F}$ and $\mathrm{V} / \mathrm{F}$ values estimated in the final model were not significantly different from the NCA values. In the final model, the relative standard error (RSE, \%) was $9.53-83.51 \%$. The Eta shrinkage values for the estimated PK parameters were suggested as acceptable at $0.02-0.40 \%$. Compared with the base model, the final model (considering total protein effects) of tiropramide reduced the IIV of V/F from $70.70 \%$ to $57.12 \%$, and the IIV of CL/F from $50.55 \%$ to $39.95 \%$. Table 6 presents the estimated parameter

\begin{tabular}{|c|c|c|c|c|c|}
\hline Parameter & Estimate & SE & RSE (\%) & Shrinkage (\%) & IIV (\%) \\
\hline \multicolumn{6}{|l|}{ Base model } \\
\hline $\operatorname{tvK}_{\mathrm{a} 1}(1 / \mathrm{h})$ & 3.160 & 0.511 & 16.143 & & \\
\hline $\mathrm{tvK}_{\mathrm{a} 2}(1 / \mathrm{h})$ & 3.171 & 0.510 & 16.086 & & \\
\hline $\mathrm{tvV} / \mathrm{F}(\mathrm{mL})$ & $1,717,060.491$ & $262,434.751$ & 15.284 & & \\
\hline tvCL/F (mL/h) & $447,163.154$ & $48,667.242$ & 10.884 & & \\
\hline $\mathrm{tvT}_{\operatorname{lag}}(\mathrm{h})$ & 0.196 & 0.021 & 10.480 & & \\
\hline$\omega^{2} \mathrm{~V} / \mathrm{F}$ & 0.500 & 0.170 & 33.973 & 0.044 & 70.701 \\
\hline$\omega^{2} \mathrm{Cl} / \mathrm{F}$ & 0.255 & 0.103 & 40.328 & 0.016 & 50.546 \\
\hline$\omega^{2} \mathrm{~T}_{\text {lag }}$ & 0.106 & 0.089 & 84.320 & 0.225 & 32.538 \\
\hline$\omega^{2} \mathrm{Ka} 1$ & 0.608 & 0.266 & 43.735 & 0.399 & 77.986 \\
\hline$\omega^{2} \mathrm{Ka} 2$ & 0.613 & 0.261 & 42.630 & 0.398 & 78.269 \\
\hline$\sigma$ & 0.354 & 0.041 & 11.673 & & \\
\hline \multicolumn{6}{|l|}{ Final model } \\
\hline $\operatorname{tvK}_{\mathrm{a} 1}(1 / \mathrm{h})$ & 3.187 & 0.538 & 16.872 & & \\
\hline $\mathrm{tvK}_{\mathrm{a} 2}(1 / \mathrm{h})$ & 3.183 & 0.524 & 16.464 & & \\
\hline $\mathrm{tvV} / \mathrm{F}(\mathrm{mL})$ & $1,889,250.002$ & $289,606.633$ & 15.329 & & \\
\hline tvCL/F (mL/h) & $466,711.101$ & $44,476.962$ & 9.530 & & \\
\hline $\mathrm{tvT}_{\text {lag }}(\mathrm{h})$ & 0.196 & 0.021 & 10.590 & & \\
\hline $\mathrm{dCl} / \mathrm{FdTotal}$ proteins & -0.804 & 0.296 & 36.791 & & \\
\hline dV/FdTotalproteins & -1.049 & 0.232 & 22.118 & & \\
\hline$\omega^{2} \mathrm{~V} / \mathrm{F}$ & 0.326 & 0.158 & 48.369 & 0.068 & 57.118 \\
\hline$\omega^{2} \mathrm{Cl} / \mathrm{F}$ & 0.160 & 0.067 & 41.977 & 0.023 & 39.947 \\
\hline$\omega^{2} \mathrm{~T}_{\text {lag }}$ & 0.107 & 0.089 & 83.508 & 0.225 & 32.503 \\
\hline$\omega^{2} \mathrm{Ka} 1$ & 0.557 & 0.276 & 49.584 & 0.405 & 74.627 \\
\hline$\omega^{2} \mathrm{Ka} 2$ & 0.556 & 0.269 & 48.406 & 0.405 & 74.566 \\
\hline$\sigma$ & 0.357 & 0.042 & 11.895 & & \\
\hline
\end{tabular}
values in the base model and final PPK model of tiropramide. The $\mathrm{AUC}_{0-\mathrm{t}}, \mathrm{AUC}_{0-\infty}, \mathrm{C}_{\max }$, half-life, and $\mathrm{T}_{\text {max }}$ estimated values by the final PPK model of tiropramide were $242.73 \pm 175.28 \mathrm{~h} \cdot \mathrm{ng} / \mathrm{mL}$, $260.92 \pm 179.08 \mathrm{~h} \cdot \mathrm{ng} / \mathrm{mL}, 54.89 \pm 46.18 \mathrm{ng} / \mathrm{mL}, 2.73 \pm 0.88 \mathrm{~h}$, and $1.65 \pm 0.53 \mathrm{~h}$, respectively.

Table 6. Population pharmacokinetic parameters for tiropramide in base model and final model. 


\subsection{Population Pharmacokinetic Model Evaluation}

The developed PPK model of the tiropramide was comprehensively evaluated for GOF, bootstrap analysis, and VPC. Figure 4 shows the GOF plots of the base and the final models of tiropramide. As shown in Figure 4B, the observed and predicted concentrations of tiropramide showed a relatively good agreement in the final model. CWRES was well distributed symmetrically with respect to zero, and CWRES was included in \pm 4 at all points. In addition, the residuals in the final model were more improved than in the base model. In other words, without any specific bias, the CWRES was randomly well distributed, and the residuals in the final model showed a significant decrease when compared with the base model (larger than \pm 4 ).

\section{A a}

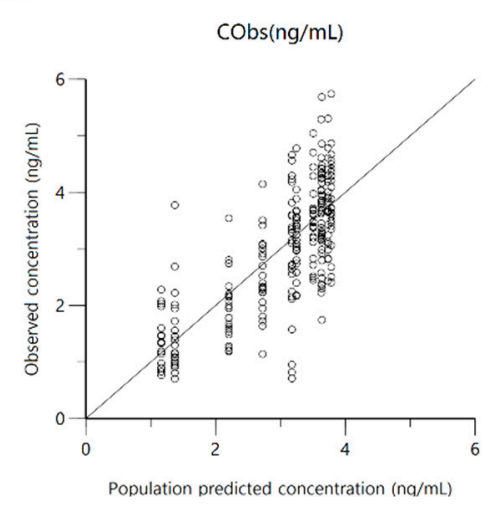

C

$\operatorname{CObs}(\mathrm{ng} / \mathrm{mL})$

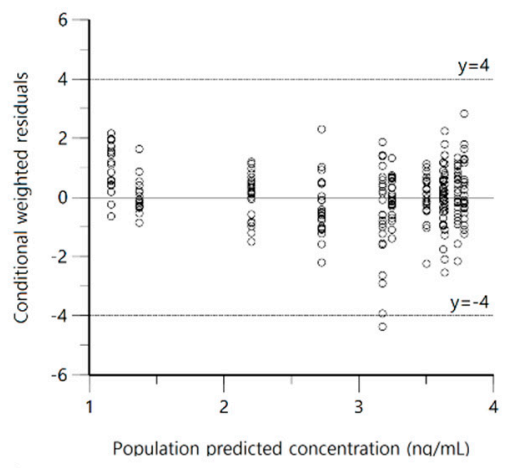

e

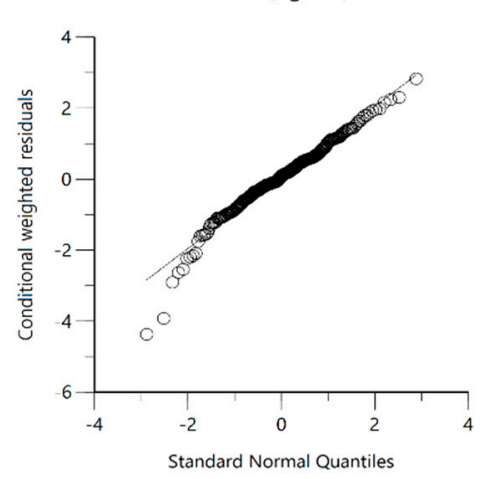

b

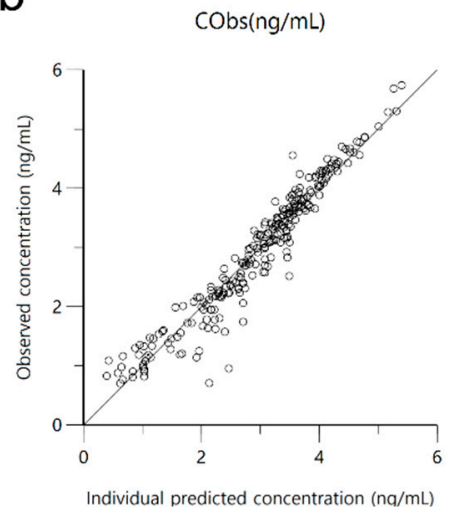

d

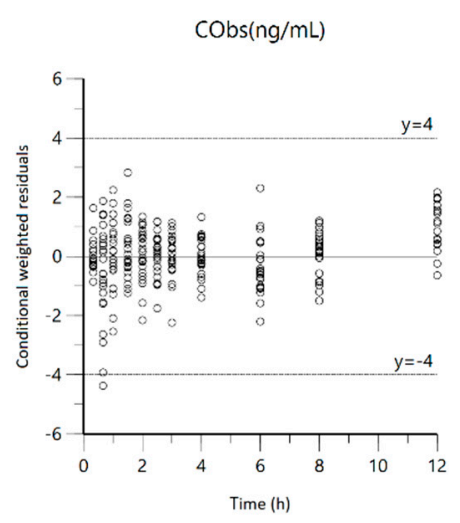

Figure 4. Cont . 
B a

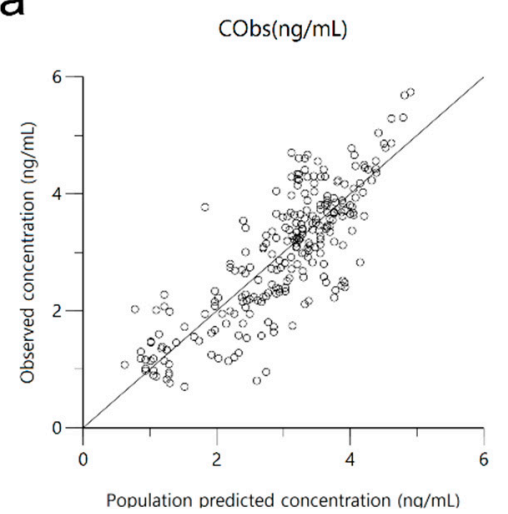

C
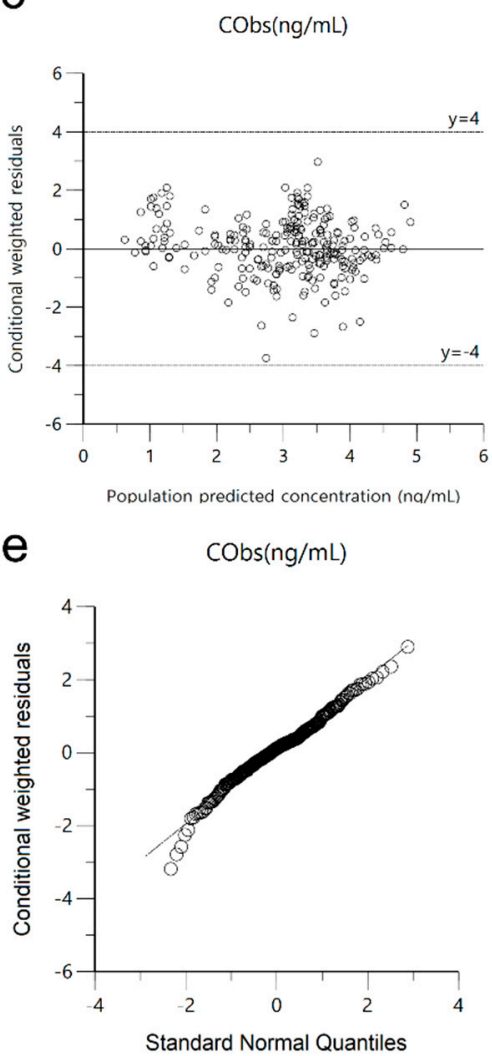

b $\quad \operatorname{cobs}(\mathrm{ng} / \mathrm{mL})$

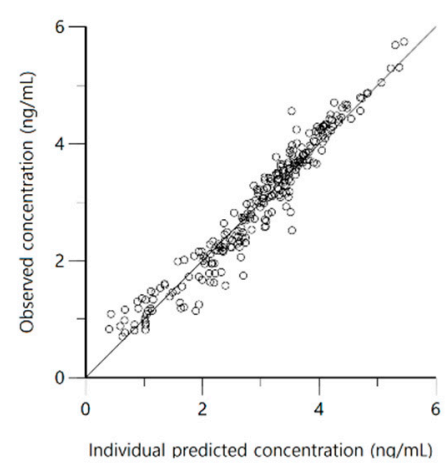

d

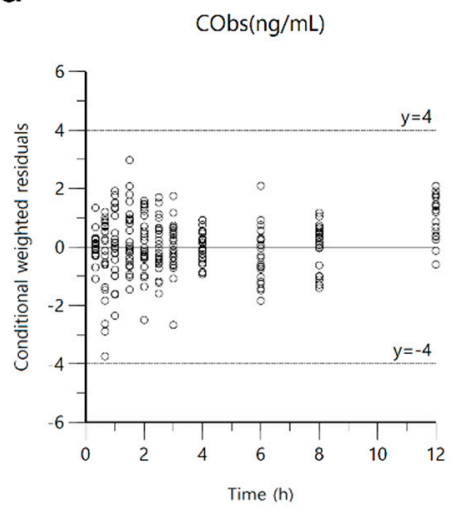

Figure 4. Goodness-of-fit (GOF) plots of base model (A) and final model (B) for tiropramide. (a) Population-predicted concentrations (PRED) against observed plasma concentration (DV), (b) individual-predicted concentrations (IPRED) against DV, (c) PRED against conditional weighted residuals (CWRES), (d) time (IVAR) against CWRES, and (e) quantile-quantile plot of components of CWRES.

Bootstrap validation was performed to verify the reproducibility and/or robustness of the final PPK model of tiropramide. Table 7 shows the bootstrapping analysis results. The parameter values estimated in the final model were in the $95 \%$ CI range of the bootstrap analysis results, and were similar to the median values of the bootstrap (replicates of 1000). 
Table 7. Estimated population pharmacokinetic parameter values of tiropramide and bootstrap validation $(n=1000)$.

\begin{tabular}{|c|c|c|c|c|}
\hline \multirow{2}{*}{ Parameter } & \multicolumn{2}{|c|}{ Final Model } & \multicolumn{2}{|c|}{ Bootstrapping } \\
\hline & Estimate & $95 \% \mathrm{CI}$ & Median & $95 \% \mathrm{CI}$ \\
\hline $\operatorname{tvK}_{\mathrm{a} 1}(1 / \mathrm{h})$ & 3.187 & $2.128-4.246$ & 3.187 & $2.332-4.733$ \\
\hline $\mathrm{tvK}_{\mathrm{a} 2}(1 / \mathrm{h})$ & 3.183 & $2.151-4.215$ & 3.183 & $2.273-4.345$ \\
\hline $\mathrm{tvV} / \mathrm{F}(\mathrm{mL})$ & $1,889,250.002$ & $1,318,770.124-2,459,730.256$ & $1,889,250.000$ & $1,397,156.042-2,491,555.125$ \\
\hline tvCL/F (mL/h) & $466,711.101$ & $379,098.212-554,324.163$ & $466,711.000$ & $374,186.003-550,036.012$ \\
\hline $\operatorname{tvT}_{\text {lag }}(\mathrm{h})$ & 0.196 & $0.155-0.237$ & 0.196 & $0.144-0.234$ \\
\hline $\mathrm{dCl} / \mathrm{FdTotalproteins}$ & -0.804 & $-1.387-(-0.221)$ & -0.804 & $-1.050-0.082$ \\
\hline $\mathrm{dV} /$ FdTotalproteins & -1.049 & $-1.506-(-0.592)$ & -1.049 & $-1.222-0.246$ \\
\hline$\omega^{2} \mathrm{~V} / \mathrm{F}$ & 0.326 & $0.017-0.636$ & 0.296 & $0.020-0.572$ \\
\hline$\omega^{2} \mathrm{Cl} / \mathrm{F}$ & 0.160 & $0.028-0.291$ & 0.134 & $0.023-0.245$ \\
\hline$\omega^{2} \mathrm{~T}_{\text {lag }}$ & 0.107 & $0.068-0.282$ & 0.085 & $0.045-0.215$ \\
\hline$\omega^{2} \mathrm{Ka} 1$ & 0.557 & $0.016-1.098$ & 0.524 & $0.016-1.063$ \\
\hline$\omega^{2} \mathrm{Ka} 2$ & 0.556 & $0.028-1.084$ & 0.518 & $0.013-1.049$ \\
\hline$\sigma$ & 0.357 & $0.273-0.441$ & 0.363 & $0.276-0.428$ \\
\hline
\end{tabular}

The VPC simulation results of the final PPK model of tiropramide are presented in Figure 5. Most of the observation values of tiropramide were well distributed within the $90 \%$ prediction interval of the prediction values. As a result, this suggests that the final model of the tiropramide is precise and explains the data well.

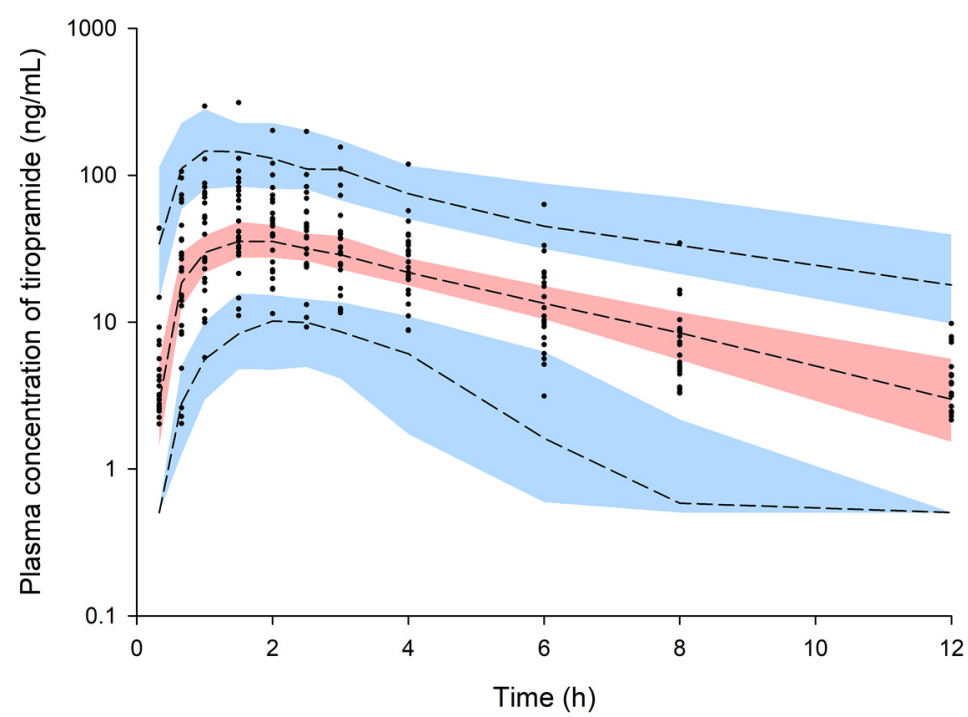

Figure 5. Visual predictive check (VPC) of the final model for tiropramide. Observed concentrations were depicted by the dots. The 95 th, 50 th, and 5 th percentiles of the predicted concentrations are represented by black dashed lines. The 95\% confidence intervals (CI) for the predicted 5th and 95th percentiles are represented by the blue shaded regions. The $95 \%$ CI for the predicted 50th percentiles are represented by the red shaded regions. The values on the $y$-axis are logarithms.

The NPDE distribution and histogram are presented in Figure S1. The assumption of a normal distribution for the differences between predictions and observations was acceptable. The quantile-quantile plots and histogram also confirmed the normality of the NPDE (Figure S1).

\section{Discussion}

The mechanism of action of tiropramide, as mentioned in the Introduction section, has been studied relatively well and has been reported in the past. However, studies on the in vivo PK characteristics (including metabolism and excretion) of tiropramide are still insufficient. Therefore, little data was available regarding the dosage and usage of tiropramide in clinical as well as formulation development. 
According to Lee et al., despite the frequent use of tiropramide in clinical practice, studies on safety and efficacy are very poor [4]. We conducted a PPK model development study of tiropramide to explore the effective covariates related to PK diversity of tiropramide and to investigate the characteristics of PK in the population. This study was new and was expected to be useful in the evaluation of the safety and efficacy of tiropramide in clinical use. As mentioned in the Abstract section, although tiropramide has a (relatively) broad margin of safety, this study involving healthy subjects was very important because it could find new covariates in healthy subjects that had not been reported before and/or be used to predict PPK for patients in the clinic by establishing PPK in healthy adults. In addition to this, in patients with abdominal pain and irritable bowel syndrome, it is very likely that the absorption process of tiropramide will change. Therefore, if clinical trials are conducted for patients in the future, it is thought that the PK variation of tiropramide between individuals can be explained more specifically through the application of our PPK model.

In this study, the PK of tiropramide was modelled as a two transit absorption phase-one compartment model with an absorption lag time. Various errors (including residual error and IIV) models and covariate effects were evaluated to establish factors that significantly influence the PK parameters of tiropramide and to explain the PK diversity of the tiropramide in the population. As a result of evaluating the model, the final tiropramide PPK model showed relatively good GOF plots, suggesting that the final PPK model had an acceptable predictive power. In addition, all CWRES values over time or predicted concentrations were in the range of -4 and 4 , suggesting that the model is relatively stable. In addition, the bootstrap and VPC simulation results suggested that the final tiropramide PPK model was accurate, stable, and precise. We compared the estimated parameter values (of $\mathrm{AUC}_{0-\mathrm{t}}, \mathrm{AUC}_{0-\infty}, \mathrm{C}_{\max }$, half-life, and $\mathrm{T}_{\max }$ ) by tiropramide's final PPK model with these values by NCA analysis. As a result, there were no significant differences $(p>0.05)$ between the parameter values predicted by the final PPK model of tiropramide and those calculated by NCA analysis. These results suggest that the final PPK model of tiropramide established in this study explains the experimental data relatively well.

The 24 healthy Korean male PK data used to establish the tiropramide PPK model were similar to the previously reported PK results. In other words, the previously reported PK parameter values of tiropramide were similar to our PK results obtained by NCA analysis. After oral administration of $100 \mathrm{mg}$ of tiropramide in humans, the obtained NCA PK parameters (as previously reported values) were 2.34-6.99 $\mathrm{h}$ for $\mathrm{t}_{1 / 2}, 0.66-1.6 \mathrm{~h}$ for $\mathrm{T}_{\max }, 77.4-111 \mathrm{ng} / \mathrm{mL}$ for $\mathrm{C}_{\max }$, and $267.7-812.7 \mathrm{~h} \cdot \mathrm{ng} / \mathrm{mL}$ for AUC $[6,12,18-21]$. On the other hand, the NCA PK parameters in this study were $3.41 \pm 1.99 \mathrm{~h}$ for $\mathrm{t}_{1 / 2}$, $1.74 \pm 0.63 \mathrm{~h}$ for $\mathrm{T}_{\max }, 69.07 \pm 59.74 \mathrm{ng} / \mathrm{mL}$ for $\mathrm{C}_{\max }$, and $280.34 \pm 199.96 \mathrm{~h} \cdot \mathrm{ng} / \mathrm{mL}$ for AUC, which were similar to the previously reported values. Table 8 summarizes these results.

As mentioned above, few studies have been done on the metabolic ratio (including pathway) and excretion of tiropramide in humans (especially patient groups), making it difficult to predict candidate covariates. On the basis of previous reports (as drug information provided by the manufacturer) that tiropramide is metabolized in the liver and excreted into urine (about $10-20 \%$ of administered dose), the covariate effects were tested in this study by obtaining the physicochemical information of liver function indicators (such as AST, ALT, and ALP) and genotyping the CYP2D6 gene related to metabolism in the body. The creatinine clearance and the functional indicator of the kidney were collected for each subject, and the covariate effects related to CL/F were tested. In addition, genotyping of genes (such as $A B C B 1, O C T 2$, and $P E P T 1$ ) associated with various transporters known to be widely involved in the distribution, absorption, excretion, and metabolism of drugs in the body has been performed to identify the effects of the covariate associated with the PK parameters. Despite these efforts, only total protein was found to have a significant effect on V/F and CL/F of tiropramide. As shown in Figure 3, the total protein, and the V/F and CL/F showed a significant negative correlation of $45.72 \%\left(r^{2}=0.209\right)$ and $45.28 \%\left(r^{2}=0.205\right)$, respectively. The correlation values of the total protein to $\mathrm{CL} / \mathrm{F}$ and $\mathrm{V} / \mathrm{F}$ were the largest of all the covariates we collected in this study. 
Table 8. Previously reported pharmacokinetic (PK) parameter values of tiropramide obtained by non-compartmental analysis (NCA) analysis.

\begin{tabular}{|c|c|c|c|c|c|c|}
\hline \multirow{2}{*}{ References } & \multirow{2}{*}{ Subjects } & \multicolumn{5}{|c|}{ PK Parameters } \\
\hline & & Half-life (h) & $\operatorname{Tmax}(h)$ & $\begin{array}{c}\mathrm{Cmax} \\
(\mathrm{ng} / \mathrm{mL})\end{array}$ & $\begin{array}{c}\mathrm{AUC}_{0-\infty} \\
(\mathrm{h} \cdot \mathrm{ng} / \mathrm{mL})\end{array}$ & CL/F (L/h) \\
\hline $\begin{array}{l}\text { Kwon et al. } \\
\text { (2003) [21] }\end{array}$ & $\begin{array}{l}\text { Human } \\
(n=2,100 \\
\text { mg dose })\end{array}$ & - & $0.66-2$ & 87.3-191.3 & $267.7-812.7$ & - \\
\hline $\begin{array}{l}\text { Kwon et al. } \\
\text { (2003) [20] }\end{array}$ & $\begin{array}{c}\text { Human } \\
(n=16,100 \\
\text { mg dose })\end{array}$ & $2.34-2.61$ & - & $96.4 \pm 51.6$ & $380.8 \pm 239.0$ & - \\
\hline $\begin{array}{l}\text { Lee et al. } \\
(2003)[6]\end{array}$ & $\begin{array}{l}\text { Human } \\
(n=4,100 \\
\text { mg dose })\end{array}$ & $2.7 \pm 0.5$ & $1.6 \pm 0.6$ & $77.4 \pm 33.0$ & $319 \pm 147$ & - \\
\hline $\begin{array}{l}\text { Baek et al. } \\
\text { (2003) [12] }\end{array}$ & $\begin{array}{c}\text { Human } \\
(n=14,100 \\
\text { mg dose })\end{array}$ & $6.3 \pm 2.0$ & $1.6 \pm 0.6$ & $111 \pm 62$ & $377 \pm 220$ & - \\
\hline $\begin{array}{l}\text { Jhee et al. } \\
\text { (2006) [19] }\end{array}$ & $\begin{array}{c}\text { Human } \\
(n=18,100 \\
\text { mg dose })\end{array}$ & $6.99 \pm 0.83$ & $1.33 \pm 0.34$ & $98.77 \pm 30.23$ & $434.39 \pm 102.35$ & - \\
\hline $\begin{array}{l}\text { Imran et al. } \\
\text { (2007) [18] }\end{array}$ & $\begin{array}{l}\text { Human } \\
(n=12,100 \\
\text { mg dose })\end{array}$ & $3.3 \pm 1.0$ & $1.5 \pm 0.2$ & $105.35 \pm 15.7$ & $375.4 \pm 76.7$ & - \\
\hline In this study & $\begin{array}{c}\text { Human } \\
(n=24,100 \\
\text { mg dose })\end{array}$ & $3.41 \pm 1.99$ & $1.74 \pm 0.63$ & $69.07 \pm 59.74$ & $280.34 \pm 199.96$ & $482.87 \pm 267.25$ \\
\hline
\end{tabular}

Although the plasma protein binding ratio of tiropramide in humans has not been reported accurately, it has been reported that the plasma protein binding ratio of tiropramide in rats is about $48-51 \%$ [22]. This suggests that the amount of plasma protein may affect the in vivo PK properties of tiropramide by binding to the plasma proteins in the blood. According to our tiropramide PPK model, higher total protein levels in the blood mean a smaller distribution of tiropramide in the body and a lower excretion. This can be explained by the fact that tiropramide binds to proteins in the blood and affects the distribution and excretion of substances from the body. Tiropramide combined with proteins in the blood will make it difficult to filter the glomerulus of the kidney and distribute from blood to many organs. The reflection of the total protein covariates in tiropramide PPK model reduced V/F IIV and CL/F IIV by $13.58 \%$ and $10.60 \%$, respectively. These results suggested that the variabilities of tiropramide plasma concentrations could be partly explained by individual variances of total protein level related with $\mathrm{V} / \mathrm{F}$ and $\mathrm{CL} / \mathrm{F}$ of tiropramide. On the other hand, other candidate covariates (such as AST, ALT, ALP, and creatinine clearance) had no significant effect on the PK parameter values and IIV improvement of tiropramide. Although tiropramide is metabolized in the liver and excreted in the kidney, our results suggest that tiropramide is a drug that does not require dose control depending on the liver and renal function. However, because our PPK model was based on the data from healthy men, further studies (for patient groups) will be needed for further clarification. That is, if PK data significantly different from the normal group (like our study) was obtained from the patient groups, and if the PPK analysis was conducted in the same manner as in this study with our model (from patient groups), other significant covariates may be identified. Therefore, PK studies or PPK analysis of tiropramide in patient groups will need to be performed in the future. Nevertheless, this study was important because it is a PPK model study of tiropramide that has not been previously conducted, and other related studies (such as clinical dose setting, formulation development, and PK comparison with certain other groups) on tiropramide may be possible in the future, on the basis of our findings. In addition, another limitation of our study was that PK analysis and PPK model studies were conducted for limited ages (between 19 and 29 years old). In the future, PK analysis and/or PPK model studies of tiropramide for more diverse age groups will need to be conducted in this regard. 
As shown in Table 6, unexplained variability (as IIV) still exists in $\mathrm{K}_{\mathrm{a}}\left(74.63 \%\right.$ for $\mathrm{K}_{\mathrm{a} 1}$ and $74.57 \%$ for $\left.\mathrm{K}_{\mathrm{a} 2}\right)$ and $\mathrm{T}_{\text {lag }}(32.50 \%)$. These results meant that multi-complex gastrointestinal (GI) tract absorption processes of tiropramide including the variabilities of each individual gastric emptying time, GI tract transit time, and other transporters, among others, could considerably affect the variabilities of tiropramide plasma concentrations. This study could not find any significant covariates that could explain $\mathrm{K}_{\mathrm{a}}$ IIV and $\mathrm{T}_{\mathrm{lag}}$ IIV. Perhaps, despite collecting various genetic and demographic information, there was still not enough information to explain the $\mathrm{K}_{\mathrm{a}}$ and $\mathrm{T}_{\text {lag }}$ IIVs of tiropramide. Therefore, further studies are needed to explore significant covariates related to the absorption of tiropramide in the body.

\section{Conclusions}

A PPK model for tiropramide was developed on the basis of PK data for healthy Korean men in this study. The plasma concentration profiles for tiropramide were described well by a two transit absorption phase-one compartment model with an absorption lag time. The total protein was identified by significant covariates of $\mathrm{CL} / \mathrm{F}$ and V/F for tiropramide, and their correlation was finally reflected in the PPK model of tiropramide. On the other hand, no significant correlation was found between genetic information such as ABCB1, CYP2D6, OCT2, PEPT1, and the PK parameters of tiropramide. To the best of our knowledge, this is the first time a PPK model has been studied for tiropramide, and it is expected to be a valuable resource for future studies (such as in clinical use, as well as dose control and formulation development).

Supplementary Materials: The following are available online at http://www.mdpi.com/1999-4923/12/4/374/s1, Figure S1: Normalized prediction distribution error (NPDE) for the final model.

Author Contributions: Research idea planning, S.-H.J., J.-H.J., and Y.-B.L.; method planning, S.-H.J. and J.-H.J.; method and data validation, S.-H.J. and H.-Y.C.; literature search, S.-H.J.; investigation, S.-H.J. and J.-H.J.; data analysis and modeling, S.-H.J. and J.-H.J.; original manuscript writing, S.-H.J. and J.-H.J.; review and editing of manuscript, S.-H.J., J.-H.J., H.-Y.C., and Y.-B.L.; supervision, Y.-B.L. All authors have read and agreed to the published version of the manuscript.

Funding: This research did not receive any specific grant from funding agencies in the public, commercial, or not-for-profit sectors.

Conflicts of Interest: The authors declare that they have no conflicts of interest relevant to this study.

\section{References}

1. Setnikar, I.; Makovec, F.; Chiste, R.; Giachetti, C.; Zanolo, G. Tiropramide and metabolites in blood and plasma after intravenous or peroral administration of 14C-tiropramide to the rat. Arzneim. Forsch. 1988, 38, 1815-1819.

2. Arigoni, R.; Chiste, R.; Drovanti, A.; Makovec, F.; Senin, P.; Setnikar, I. Pharmacokinetics of tiropramide after single doses in man. Arzneim. Forsch. 1986, 36, 738-744.

3. Arigoni, R.; Chiste, R.; Makovec, F.; Setnikar, I.; Benfenati, E.; Fanelli, R. Identification of metabolites of tiropramide in human urine. Biomed. Environ. Mass Spectrom. 1988, 15, 205-209. [CrossRef] [PubMed]

4. Lee, K.N.; Lee, O.Y.; Choi, M.-G.; Sohn, C.I.; Huh, K.C.; Park, K.S.; Kwon, J.G.; Kim, N.; Rhee, P.-L.; Myung, S.-J.; et al. Efficacy and safety of tiropramide in the treatment of patients with irritable bowel syndrome: A multicenter, randomized, double-blind, non-inferiority trial, compared with octylonium. J. Neurogastroenterol. Motil. 2014, 20, 113-121. [CrossRef] [PubMed]

5. Kim, S.-M.; Lee, S.-N.; Yoon, H.; Kang, H.-A.; Cho, H.-Y.; Lee, I.-K.; Lee, Y.-B. Haplotype analysis and single nucleotide polymorphism frequency of organic cation transporter gene (OCT1 and 2) in Korean subjects. J. Pharm. Investig. 2009, 39, 345-351. [CrossRef]

6. Lee, H.W.; Ji, H.Y.; Kim, H.H.; Cho, H.-Y.; Lee, Y.-B.; Lee, H.S. Determination of tiropramide in human plasma by liquid chromatography-tandem mass spectrometry. J. Chromatogr. B 2003, 796, 395-400. [CrossRef]

7. Kim, S.-M.; Lee, S.-N.; Kang, H.-A.; Cho, H.-Y.; Lee, I.-K.; Lee, Y.-B. Haplotype analysis and single nucleotide polymorphism frequency of PEPT1 gene (Exon 5 and 16) in Korean. J. Pharm. Investig. 2009, 39, 411-416. [CrossRef] 
8. Kim, S.-M.; Park, S.-A.; Cho, H.-Y.; Lee, Y.-B. Haplotype analysis of MDRI gene (Exon 12, 21 and 26) in Korean. J. Pharm. Investig. 2008, 38, 365-372.

9. Gaedigk, A.; Simon, S.; Pearce, R.; Bradford, L.; Kennedy, M.; Leeder, J. The CYP2D6 activity score: Translating genotype information into a qualitative measure of phenotype. Clin. Pharmacol. Ther. 2008, 83, 234-242. [CrossRef]

10. Lee, S.-Y.; Sohn, K.M.; Ryu, J.Y.; Yoon, Y.R.; Shin, J.G.; Kim, J.-W. Sequence-based CYP2D6 genotyping in the Korean population. Ther. Drug Monit. 2006, 28, 382-387. [CrossRef]

11. Byeon, J.-Y.; Kim, Y.-H.; Lee, C.-M.; Kim, S.-H.; Chae, W.-K.; Jung, E.-H.; Choi, C.-I.; Jang, C.-G.; Lee, S.-Y.; Bae, J.-W. CYP2D6 allele frequencies in Korean population, comparison with East Asian, Caucasian and African populations, and the comparison of metabolic activity of CYP2D6 genotypes. Arch. Pharm. Res. 2018, 41, 921-930. [CrossRef] [PubMed]

12. Baek, S.K.; Lee, S.S.; Park, E.J.; Sohn, D.H.; Lee, H.S. Semi-micro high-performance liquid chromatographic analysis of tiropramide in human plasma using column-switching. J. Pharm. Biomed. Anal. 2003, 31, 185-189. [CrossRef]

13. Deurenberg, P.; Weststrate, J.A.; Seidell, J.C. Body mass index as a measure of body fatness: Age-and sex-specific prediction formulas. Br. J. Nutr. 1991, 65, 105-114. [CrossRef] [PubMed]

14. Mosteller, R. Simplified calculation of body surface area. N. Engl. J. Med. 1987, 317, 1098.

15. Cockcroft, D.W.; Gault, M.H. Prediction of creatinine clearance from serum creatinine. Nephron 1976, 16, 31-41. [CrossRef]

16. Comets, E.; Brendel, K.; Mentré, F. Computing normalised prediction distribution errors to evaluate nonlinear mixed-effect models: The npde add-on package for R. Comput. Methods Programs Biomed. 2008, 90, 154-166. [CrossRef]

17. Deardorff, O.G.; Jenne, V.; Leonard, L.; Ellingrod, V.L. Making sense of CYP2D6 and CYP1A2 genotype vs. phenotype. Curr. Psychiatry 2018, 17, 41-45.

18. Imran, K.; Punnamchand, L.; Natvarlal, S.M. A simple sample preparation with HPLC-UV method for estimation of tiropramide from plasma: Application to bioequivalence study. J. Pharm. Biomed. Anal. 2007, 43, 1135-1140. [CrossRef]

19. Jhee, O.H.; Jeon, Y.C.; Choi, H.S.; Lee, M.H.; Om, A.S.; Lee, J.-W.; Hong, J.W.; Kim, Y.S.; Kang, J.C.; Lee, Y.S. Quantitative analysis of tiropramide in human plasma by gas chromatography coupled to mass spectrometry for application to a bioequivalence test. Clin. Chim. Acta 2006, 366, 179-184. [CrossRef]

20. Kwon, O.-S.; Park, Y.-J.; Chung, Y.-B. Pharmacokinetics and bioequivalence of tiropramide in healthy volunteers. Arzneim. Forsch. 2003, 53, 578-583. [CrossRef]

21. Kwon, O.-S.; Park, Y.-J.; Ryu, J.-C.; Chung, Y.B. Quantitative analysis of tiropramide in human blood by gas chromatography with nitrogen-phosphorus detector. Arch. Pharm. Res. 2003, 26, 416-420. [CrossRef] [PubMed]

22. Abe, H.; Inokawa, Y.; Yasuda, E.; Nishioka, Y.; Esumi, Y.; Nemoto, H.; Inaba, A.; Jin, Y.; Ninomiya, S. Pharmacokinetic studies of tiropramide in rats (I). Absorption, distribution, metabolism and excretion after single administration. Yakuri Chiryo 1992, 20, 113-129.

(C) 2020 by the authors. Licensee MDPI, Basel, Switzerland. This article is an open access article distributed under the terms and conditions of the Creative Commons Attribution (CC BY) license (http://creativecommons.org/licenses/by/4.0/). 